Minireview

\title{
Recent advances in Trop 2 targeted therapy for solid tumors
}

\author{
Shutan Liao ${ }^{1, *}$, Bing Wang $^{l}$, Rong Zeng ${ }^{l}$, Haifeng Bao ${ }^{l}$, Xiaomin Chen ${ }^{l}$, Rakesh Dixit ${ }^{2}$ and \\ Xiaoyan Xing ${ }^{1, *}$ \\ ${ }^{1}$ Amador Bioscience Ltd, Hangzhou, China \\ ${ }^{2}$ Bionavigen LLC, Maryland, USA
}

Abbreviated Title: Recent advances in Trop 2 targeted therapy

*Address for correspondence:

Xiaoyan Xing, MD, PhD

260 No.6 Street, Building 19, Suite 318,

Qiantang New Area, Hangzhou,

Zhejiang, China

310018

Email: xiaoyan.xing@amadorbio.com

Shutan Liao, MD, PhD

260 No.6 Street, Building 19, Suite 318, Qiantang New Area, Hangzhou,

Zhejiang, China

310018

Email: harry.liao@amadorbio.com

\begin{abstract}
Trophoblast cell-surface antigen 2 (Trop 2) is a transmembrane glycoprotein that is highly expressed in various cancer types with relatively low or no baseline expression in most of normal tissues. Its overexpression is associated with tumor growth and poor prognosis; Trop 2 is therefore, an ideal therapeutic target for epithelial cancers. Several Trop 2 targeted therapeutics have recently been developed for the treatment of cancers, such as anti-Trop 2 antibodies and antibody-drug conjugates (ADCs), as well as Trop 2-specific cell therapy. In particular, the safety and clinical benefit of Trop 2-based ADCs have been demonstrated in clinical trials across multiple tumor types, including those with limited treatment options, such as triple-negative breast cancer, platinum-resistant urothelial cancer, and heavily pretreated non-small cell lung cancer. In this review, we elaborate on recent advances in Trop 2 targeted modalities and provide an overview of novel insights for future developments in this field.
\end{abstract}

Keywords: Trop 2, targeted therapy, antibody-drug conjugate, solid tumors

\section{Introduction}

Trophoblast cell-surface antigen 2 (Trop 2) is a transmembrane glycoprotein encoded by Tumor-associated calcium signal transducer 2 (TACSTD2) gene located in chromosome 1p32. Trop 2 was first identified in trophoblast cells and choriocarcinomas by monoclonal antibodies against the human choriocarcinoma cell line and later also known as gastrointestinal antigen 733-1 (GA733-1), membrane component chromosome 1 surface marker 1 (M1S1) and 
epithelial glycoprotein-1 (EGP-1) in sequential discoveries [1-3]. Since the discovery of Trop 2 in the placenta, accumulating evidence suggests that Trop 2 may play a role in tumor development as being involved in several growth-stimulatory signaling pathways [3]. Also, overexpression of Trop 2 correlates with poor prognosis in various solid tumors [4]. Therefore, Trop 2 is considered an attractive prognostic marker and a therapeutic target for the treatment of solid tumors. To date, a series of Trop 2 targeted modalities, such as antibodies, antibodydrug conjugates (ADCs), and immunotherapy, have been reported. In April 2020, the first Trop 2 targeting drug sacituzumab govitecan, an anti-Trop 2 ADC, was approved in the US for the treatment of metastatic triple-negative breast cancer (TNBC), spurring more research into the biology of Trop 2 and the development of different types of Trop 2 targeting drugs for not only TNBC but also other solid tumors.

\section{Structure of Trop 2}

The Trop 2 protein consists of 323 amino acids with a single hydrophobic peptide, an extracellular region containing a thyroglobulin type- 1 repeat domain and a putative epidermal growth factor (EGF)-like domain, a transmembrane domain, and a cytoplasmic tail (Figure 1) [5]. Thyroglobulin type-1 repeats are cysteine-rich motifs with strictly conserved positions for cysteine residues, and occasionally act as an inhibitor of proteases [6]. The putative EGF-like domain may bind to specific growth factors and regulate the downstream signaling pathways [7]. The cytoplasmic tail exhibits structural and sequence homology to a HIKE domain, which is a regulatory region for protein-protein interactions, as well as contains a protein kinase $\mathrm{C}$ (PKC) phosphorylation site and a phosphatidyl-inositol 4,5-bisphosphate (PIP2) binding sequence, supporting the role of Trop 2 in calcium signaling [8-10]. Trop 2 has been reported to bind to several proteins, such as insulin-like growth factor 1 (IGF-1), claudin-1 and -7, cyclin $\mathrm{D} 1$, and $\mathrm{PKC}$, and be involved in various cellular processes, including proliferation and apoptosis [11].

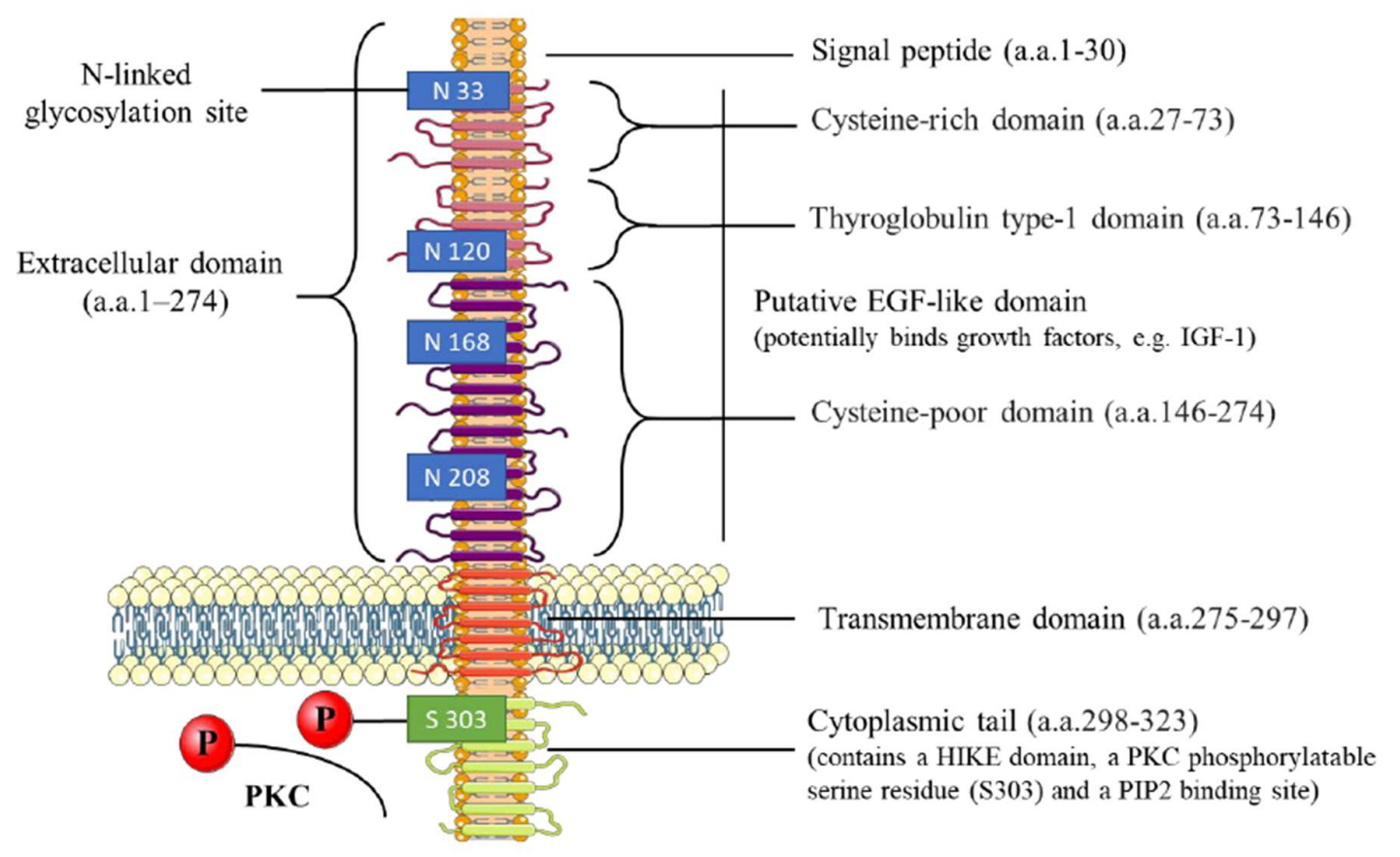

Figure 1. Structure of Trop 2 protein.

The Trop 2 protein contains a 30-amino-acid signal peptide and 244-amino acid extracellular domain with $4 \mathrm{~N}$ linked glycosylation sites [98]. The 244-amino-acid extracellular portion has a cysteine-rich domain, a thyroglobulin type-1 domain, a cysteine-poor domain, as well as a putative epidermal growth factor (EGF)-like 
domain which potentially binds to growth factors, such as insulin-like growth factor 1 (IGF-1) [7]. The Trop 2 molecule traverses the membrane and terminates with a 26-amino acid cytoplasmic tail [99]. The cytoplasmic tail exhibits structural and sequence homology to a HIKE domain and contains a serine residue (Ser303) that is phosphorylated by protein kinase C (PKC), and a phosphatidyl-inositol 4,5-bisphosphate (PIP2) binding site. The presence of those structures supports the involvement of Trop 2 in calcium signaling [2]

\section{Expression of Trop 2}

Typically, Trop 2 is mainly expressed in epithelial cells and plays an essential role in embryonic and fetal development [5]. Trop 2 mRNA and protein can be detected in many normal tissues, in particular, highly expressed at both the transcript and protein levels in skin, trachea, pancreas, kidneys, cervix, and uterus, though the cellular location of Trop 2 expression on normal tissues is highly variable $[12,13]$. In contrast, Trop 2 is highly expressed and inducible in diverse epithelial cancers, regardless of baseline expression in corresponding normal tissues [3]. Overexpression of Trop 2 was reported to be a valuable prognosis predictive biomarker in various epithelial cancers, such as head and neck squamous cell carcinoma, gastric cancer, gallbladder cancer, cervical cancer, lung cancer, breast cancer, colon cancer, pancreatic cancer, ovarian carcinoma, endometrioid endometrial carcinoma [14-23]. In a meta-analysis involving 16 studies and 2,569 participants, Trop 2 overexpression was shown to be associated with poor overall survival and disease-free survival in those patients with solid tumors [4].

Notedly, the overexpression of Trop 2 was most significant in certain types of cancers, such as breast and lung cancer, and thus, Trop 2 becomes an attractive therapeutic target for cancer treatment (Figure 2). It has been reported that overexpression of Trop 2 was present in over $80 \%$ of TNBC and was associated with lymph node status, metastasis, and tumor grade, as well as poor prognosis in breast cancers [24-26]. Moreover, Trop 2 activation state, presented as membrane-localized and glycosylated Trop 2, has been considered as critical determinants of tumor progression and indicators of breast cancer patient's survival [23]. Several studies revealed that Trop 2 was highly expressed in over $60 \%$ of squamous cell carcinoma and $42-$ $64 \%$ of adenocarcinoma, where overexpressed Trop 2 promoted cell proliferation, invasion, and neovascularization [27-30]. High expression of Trop 2 is also closely correlated with an unfavorable prognosis in advanced non-small-cell lung cancer (NSCLC) [31]. However, a few studies also suggested that overexpression of Trop 2 appeared to inhibit rather than promote tumorigenesis in lung adenocarcinoma [7,22]. One possible explanation for this puzzle is that Trop 2 could compete with the IGF-1 receptor (IGF-1R) for the shared IGF-1 ligand and attenuate IGF-1R signaling. Being a tumor promoter, highly expressed Trop 2 may outcompete the pro-oncogenic IGF-1 receptor, thus promote a malignant status. On the contrary, Trop 2 with low expression would lose its suppressive effect on IGF-1R signaling, and the tumor grows via the IGF-1R pro-oncogenic pathway [32]. Nevertheless, Trop 2 typically promotes and less frequently suppresses tumor progression, depending on the histotype [32]. Considering the baseline expression of Trop 2 in normal tissues, the successful development of Trop 2 targeted therapies require strategies that can minimize potential toxicities to Trop 2, expressing normal tissues. 


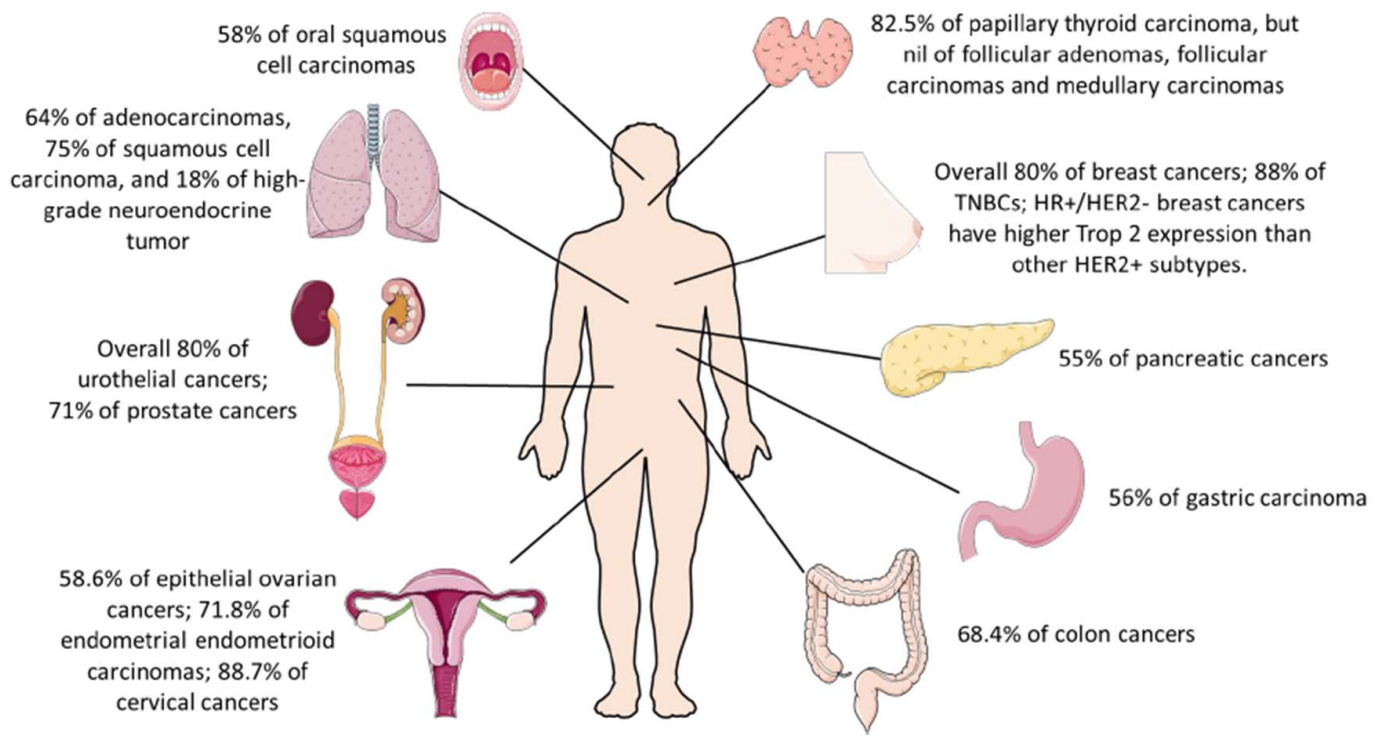

Figure 2. Overexpression of Trop 2 antigen in cancers

Trop 2 is overexpressed, presented as moderate to strong membranous and/or cytoplasmic immunohistochemistry (IHC) positivity, in the majority of epithelial carcinomas, including breast, lung, colon, prostate, gastric, pancreatic, thyroid, urothelial cancers, as well as female reproductive system cancers (The Human Protein Atlas. http://www.proteinatlas.org/ENSG00000184292-TACSTD2/gene). Trop 2 was overexpressed in approximately $80 \%$ of breast cancers, and $88 \%$ of TNBCs $[13,23,24]$. HR+/HER2- breast cancers have shown significantly higher Trop 2 expression than have other HER2+ subtypes [103]. High Trop 2 expression was observed in 64\% of lung adenocarcinomas, $75 \%$ of lung squamous cell carcinomas, and $18 \%$ of lung high-grade neuroendocrine tumors [30]. The protein of Trop 2 was overexpressed in $58.6 \%$ of epithelial ovarian cancers and $71.8 \%$ of endometrial endometrioid carcinomas [49,104]. Trop 2 was highly expressed in cervical cancers $(88.7 \%)$, and the increased expression of Trop 2 was associated with the increase of cervical intraepithelial neoplasia (CIN) grades [14]. $68.4 \%$ of colon cancers had high expression of Trop 2 [19]. Overall $80 \%$ of urothelial cancers and $71 \%$ of prostate cancers had moderate to strong Trop 2 expression $[13,105]$. The majority of papillary thyroid carcinomas $(82.5 \%)$ were overexpressed for Trop 2, but the Trop 2 immunostaining of follicular adenomas, follicular carcinomas and medullary carcinomas were negative [106]. Trop 2 overexpression was observed in 55\% pancreatic cancers, $56 \%$ of gastric carcinomas and $58 \%$ of oral squamous cell carcinomas $[16,107,108]$.

\section{Signaling of Trop 2}

Trop 2 regulates several signaling molecules and participates in signaling pathways associated with tumorigeneses, such as calcium signaling, $\beta$-catenin signaling, cyclin expression, and fibronectin adhesion (Figure 3) [33-36]. The signaling network of Trop 2 in cancer growth has been comprehensively reviewed previously [11,37]. Trop 2 upregulation promotes the expression and activation of several downstream effectors, such as NF-kB, STAT1, and STAT3, through induction of the cyclin D1 and extracellular signal-regulated kinase $(\mathrm{ERK}) /$ mitogen-activated protein kinase (MAPK) kinase (MEK) signaling pathways, contributing to cell survival and growth. Trop 2 regulates integrin-dependent signaling for cell adhesion and migration by facilitating the re-localization of cytoplasmic RACK1 to the cell membrane, reducing the fibronectin-binding to integrin $\beta-1$, thereby decreasing cell adhesion and promoting cell invasion and metastasis [38]. The co-expression of upstream/downstream tumor-growth-regulatory transcription network hubs and interacting partners in human tumors also supports the role of the Trop 2 signaling network in oncogenesis [35]. Moreover, overexpression of wild-type Trop 2 appears to be necessary and sufficient to promote tumor growth, supported by the evidence that the rate of tumor growth was proportional to the 
expression levels of Trop 2 and somatic knockdown of Trop 2 essentially abolished the growth of Trop 2 overexpressing tumor cells [13]. Different from the classic, cell-transforming oncogenes often activated by mutations, there were no data showing tumor-related structural alterations/point mutations of Trop 2, or Trop 2 induced oncogenic transformations $[11,13]$. The tumor growth-promoting role of Trop 2 has thus been defined as "non-oncogene addiction," being frequently upregulated and essential in sustaining tumor phenotype driven by oncogenes via a compensatory mechanism [39]. Nevertheless, current data support the role of overexpressed Trop 2 as a potent driver of human tumor growth.

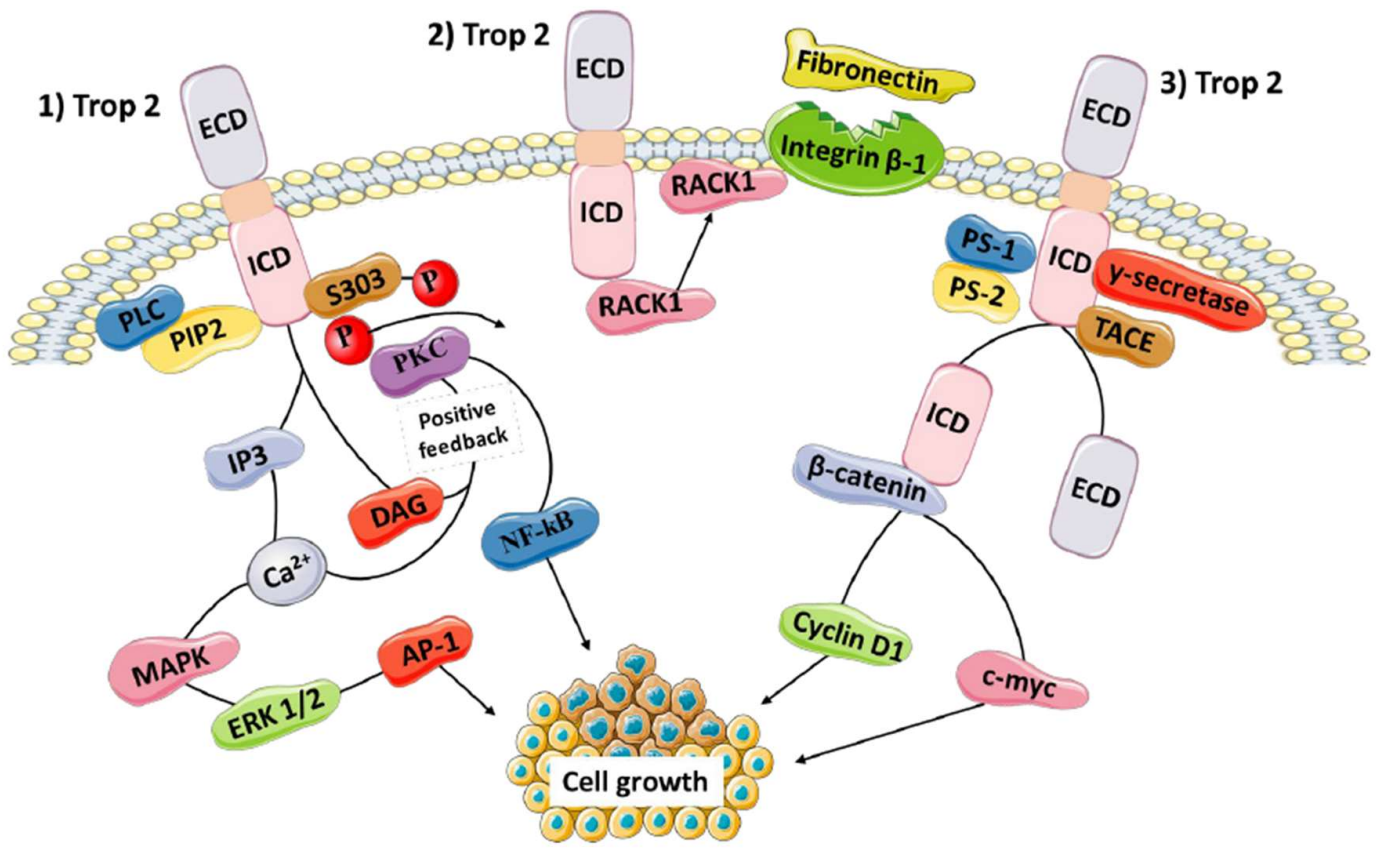

Figure 3. The Trop 2 associated oncogenic signaling pathways

Trop 2 is a membrane-bound protein consists of an extracellular domain, a single transmembrane domain, and an intracellular region. Trop 2 promotes cell growth, proliferation, and tumor metastasis by modulating calcium signaling and cyclin expression as well as reducing fibronectin adhesion. 1) Once the serine residues (S303) of cytoplasmic tail are phosphorylated by protein kinase $\mathrm{C}(\mathrm{PKC})$, it facilitates the hydrolysis of 4, 5-diphosphate phosphatidylinositol (PIP2) into inositol 1,4,5-triphosphate (IP3) and deacylglycerol (DAG) by phospholipase C (PLC). IP3 interacts with IP3 receptors and causes the release of calcium ions from the endoplasmic reticulum, activating mitogen activated protein kinase (MAPK) and subsequently increasing levels of phosphorylated extracellular signal-regulated kinase (ERK) 1/2 [100]. Activated ERK signaling results in induction of the activator protein 1 (AP-1) transcription factor which is the key regulator of tumor-associated target genes during oncogenesis [101]. The increase in free $\mathrm{Ca}^{2+}$ and DAG could also in turn activate PKC in a positive feedback manner and leads to the activation of the NF- $\mathrm{B}$ pathways [3]. 2) Trop 2 assists with the localization of cytoplasmic RACK1 to the cell membrane, bringing it close to integrin $\beta$-1, reducing the fibronectin binding to integrin $\beta-1$, thereby decreasing cell adhesion and promoting cell invasion and metastasis [38]. 3) Several enzymes, such as TNF- $\alpha$ converting enzyme (TACE), y-secretase, presenilin 1/2 (PS-1, PS-2), are involved in the cleavage of the Trop 2 protein into two products: the intracellular domain (ICD) and the extracellular domain (ECD). The $\beta$-catenin colocalizes with the ICD in the nucleus and upregulates the expressions of downstream cyclin D1 and c-myc, which leads to cell growth [102].

\section{Trop 2 targeted therapy}

\subsection{Anti-Trop 2 Antibodies}

The production of autoantibodies in tumor patients is believed to represent reinforced immunologic reactivity and immune surveillance for malignant cells [40]. In most cases, it is 
the result of the abnormal expression and/or alteration in the structure of the corresponding antigen [41]. It is reported that anti-Trop 2 autoantibodies were present in the serum of $31 \%$ of patients with esophageal squamous cell carcinoma in cases from the serological analysis of recombinant cDNA expression libraries (SEREX). The serum level of Trop 2 autoantibodies was correlated with tumor size, implicating that Trop 2 could be immunogenic in cancer patients [42]. An earlier study revealed that Trop 2 could be recognized by human cytotoxic $\mathrm{T}$ lymphocytes (CTLs); meanwhile, Trop 2 specific CTLs exhibited high specific cytotoxic properties against corresponding transfected target cells [43]. A potential role of Trop 2 in immunotherapy is therefore suggested. Subsequently, a series of "artificial" therapeutic monoclonal antibodies (mAbs) were developed. A murine specific monoclonal anti-Trop 2 antibody RS7-3G11 (RS7) with pancarcinoma reactivity raised against human lung squamous cell carcinomas and a humanized equivalent of this antibody (hRS7) have demonstrated in vitro antitumor activities in a wide variety of tumors, such as breast cancer, lung adenocarcinoma, ovarian, uterine and cervical carcinomas [43-49]. RS7 is rapidly internalized upon binding to the target cells, and as such, can be a potential candidate for immunoconjugates [44]. Indeed, radio-labeled or ranpirnase-fused RS7 has been reported to effectively target and treat cancer xenografts in nude mice in several studies [44,50-52]. Moreover, a human antigen-binding fragment $(\mathrm{Fab})$ against Trop 2 extracellular domain isolated from the phage library exhibited inhibitory effects on tumor growth by inducing apoptosis in both invasive breast ductal carcinoma cells and breast cancer xenografts [53]. Although several anti-Trop 2 antibodies have been generated, they did not present significant antitumor activities in in vivo model when used as naked antibodies without conjugation with drugs, toxins or radioisotopes until the development of two novel anti-Trop 2 antibodies AR47A6.4.2 and Pr1E11 showing significant antitumor activity in vivo [54,55]. With low internalization activity and high cell surface retention, those antibodies displayed potent in vivo antibody-dependent cellular cytotoxicity (ADCC) and/or complement-dependent cytotoxicity (CDC) activities in pancreatic, colon, breast and prostate human cancer models, suggesting the potential therapeutic value of antiTrop 2 antibodies for the treatment of solid tumors [54-56]. However, no further data have been reported recently.

Various cytotoxic $\mathrm{T}$ cells redirecting bispecific antibodies have demonstrated therapeutic efficacy in preclinical and clinical settings by binding two different antigens located on $\mathrm{T}$ cells and tumor cells [57]. A trivalent bispecific antibody comprising an anti-CD3 scFv covalently linked to a stabilized dimer of a Trop 2 targeting Fab had been shown to effectively induce T cell mediated killing of Trop 2 expressing cancer cells in vitro and in vivo, suggesting the potential use of Trop 2 as a target through immunologic synapses induced by a bispecific antibody [58,59].

\subsection{Small molecule inhibitor}

Small molecules and antibodies are two major approaches for targeted cancer therapy. Antibodies typically possess high specificity and affinity to their targets which are normally restricted to the cell surface. By contrast, small molecule inhibitors vary in selectivity but can target a wide range of extracellular and intracellular proteins. Currently no small molecule inhibitors of Trop 2 are in development, likely because of complexity of the function of the Trop 2 protein as well as the compensatory role of Trop 2 in oncogenesis. As aforementioned, Trop 2 can bind to several proteins through its own different structures/domains to regulate downstream pathways in a complex signaling network [35]. It is challenging to develop a small molecule drug with inhibitory function, but cytotoxic small molecule drugs conjugated to antiTrop 2 antibodies (ie ADCs) have been proved to be effective clinically in cancer treatment. 


\subsection{Trop 2 ADCs}

Despite the poor clinical success and minimal antitumor effects of unarmed monoclonal antiTrop 2 antibodies, their specificity for the target and the rapid internalization upon target binding make such antibodies ideal carriers for the delivery of cytotoxic agents to Trop 2 expressing tumors. ADCs represent a novel class of therapeutics that consists of a tumor associated antigen (TAA)-targeting antibody and a cytotoxic agent conjugated to the antibody via a linker [60]. The structures of Trop 2 ADC products currently in human clinical trials are summarized in Table 1. Typically, the TAA should be highly expressed on the surface of tumor cells but with minimal or no expression on normal tissues with high blood flow, high metabolic rate, and critical for survival, leading to selective delivery and internalization of the cytotoxic agent (payload) to tumor cells [61]. Moreover, the chemistry of the linker, being non-cleavable or cleavable, determines unique characteristics of a certain ADC. An ADC may also mediate bystander killing effect on surrounding antigen-negative tumor cells, although the bystander effect largely depends on whether the cytotoxic payload can diffuse into surrounding cells [61]. The dose-limiting toxicity of ADCs in cancer patients seems to be more closely related to the cytotoxic payload other than the targeted antigen $[62,63]$.

Table 1. The structures of Trop 2 ADC products currently in human clinical trials.

\begin{tabular}{|c|c|c|c|c|c|c|c|}
\hline $\begin{array}{l}\text { ADC } \\
\text { Products }\end{array}$ & Company & Antibody & Linker & $\begin{array}{l}\text { Conjugation } \\
\text { Method }\end{array}$ & Payload & DAR & Ref \\
\hline $\begin{array}{l}\text { PF- } \\
\text { 06664178 } \\
\text { (RN927C } \\
\text { ) }\end{array}$ & Pfizer & $\begin{array}{l}\text { A } \\
\text { humanized } \\
\text { hIgG1 } \\
\text { antibody }\end{array}$ & Cleavable & $\begin{array}{l}\text { Site-specific } \\
\text { transglutamin } \\
\text { ase-mediated }\end{array}$ & $\begin{array}{l}\text { Auristatin } \\
\text { microtubule } \\
\text { inhibitor } \\
\text { (Aur0101) }\end{array}$ & 2 & {$[64]$} \\
\hline $\begin{array}{l}\text { Sacituzu } \\
\text { mab } \\
\text { govitecan } \\
\text { (IMMU- } \\
\text { 132) }\end{array}$ & $\begin{array}{l}\text { Immunom } \\
\text { edics }\end{array}$ & $\begin{array}{l}\text { A } \\
\text { humanized } \\
\text { RS7 IgG1к }\end{array}$ & $\begin{array}{l}\text { Less } \\
\text { stable } \\
\text { cleavable } \\
\text { (pH- } \\
\text { sensitive) }\end{array}$ & Site-specific & $\begin{array}{l}\text { Active metabolite } \\
\text { of irinotecan (SN- } \\
38 \text { ) }\end{array}$ & 7.6 & [109] \\
\hline $\begin{array}{l}\text { Datopota } \\
\text { mab } \\
\text { deruxteca } \\
\text { n (DS- } \\
1062)\end{array}$ & $\begin{array}{l}\text { Daiichi } \\
\text { Sankyo }\end{array}$ & $\begin{array}{l}\text { A } \\
\text { humanized } \\
\text { antibody }\end{array}$ & $\begin{array}{l}\text { Cleavable } \\
\text { (tetrapepti } \\
\text { de-based) }\end{array}$ & $\begin{array}{l}\text { Site-specific } \\
\text { (cysteine } \\
\text { residue of the } \\
\text { antibody) }\end{array}$ & $\begin{array}{l}\text { A novel DNA } \\
\text { topoisomerase I } \\
\text { inhibitor, exatecan } \\
\text { derivative (DXd) }\end{array}$ & 4 & [81] \\
\hline BAT8003 & $\begin{array}{l}\text { Bio-Thera } \\
\text { Solutions }\end{array}$ & $\begin{array}{l}\text { A } \\
\text { glycoengine } \\
\text { ered } \\
\text { humanized } \\
\text { antibody }\end{array}$ & $\begin{array}{l}\text { Non- } \\
\text { cleavable }\end{array}$ & $\begin{array}{l}\text { Site-specific ( } \\
\text { A114C } \\
\text { mutation on } \\
\text { antibody } \\
\text { heavy chain) }\end{array}$ & $\begin{array}{l}\text { Maytansine } \\
\text { derivative } \\
\text { (Batansine) }\end{array}$ & 3.5 & [84] \\
\hline SKB264 & $\begin{array}{l}\text { Klus } \\
\text { Pharma }\end{array}$ & $\begin{array}{l}\text { A } \\
\text { humanized } \\
\text { antibody }\end{array}$ & Unknown & $\begin{array}{l}\text { Novel stable } \\
\text { conjugation } \\
\text { chemistry }\end{array}$ & Belotecan-derived & 7.2 & {$[86]$} \\
\hline DAC-002 & $\begin{array}{l}\text { DAC } \\
\text { Biotech }\end{array}$ & $\begin{array}{l}\text { A } \\
\text { humanized } \\
\text { antibody }\end{array}$ & Unknown & Unknown & $\begin{array}{l}\text { Tubulysin B } \\
\text { analogue }\end{array}$ & $\begin{array}{l}\text { Un- } \\
\text { know } \\
\text { n }\end{array}$ & NA \\
\hline
\end{tabular}

\subsubsection{PF-06664178}

PF-06664178 is an ADC composed of a humanized anti-Trop 2 IgG1 antibody conjugated with an auristatin microtubule inhibitor (Aur0101) via a cleavable linker. PF-06664178 has a low antibody-drug ratio (DAR) of 2, so a more potent payload, Aur0101, was selected to achieve sufficient tumoricidal activity [64]. A Phase I, dose-escalation study (NCT02122146) was conducted to evaluate the safety and preliminary antitumor activity of PF-06664178 in patients with advanced or metastatic solid tumors [65]. Thirty-one patients received PF-06664178 in 
escalating doses from 0.15 to $4.8 \mathrm{mg} / \mathrm{kg}$, and dose-limiting toxicities were observed at $\geq 3.6$ $\mathrm{mg} / \mathrm{kg}$ dose levels. While 11 patients had stable disease (SD) as the best overall response, none achieved a complete response (CR) or partial response (PR). The study was prematurely discontinued due to a lack of a meaningful therapeutic window.

5.3.2. Sacituzumab Govitecan

Sacituzumab govitecan (IMMU-132; Trodelvy ${ }^{\mathrm{TM}}$ ) developed by Immunomedics is an ADC that consists of a humanized anti-Trop 2 monoclonal antibody (hRS7), conjugated with active metabolite of irinotecan ( $\mathrm{SN}-38$ ) via a cleavable CL2A linker. The utilization of a pH-sensitive, cleavable linker facilitates the cytotoxic activity to target-expressing and bystander tumor cells via internalization and local release of the cytotoxic drug at the tumor site. The payload SN-38 is a moderately-cytotoxic drug and conjugated to hRS7 at a high DAR of 8 without affecting Trop 2 targeting and antibody pharmacokinetics [66].

In April 2020, sacituzumab govitecan received an accelerated FDA approval to treat adult patients with metastatic TNBC (mTNBC) who have received at least two prior therapies for metastatic disease [67]. Sacituzumab govitecan is not only the first ADC approved specifically for mTNBC, but also the first FDA approved anti-Trop 2 ADC. The approval was based on the results of IMMU-132-01, a multi-center, single-arm clinical trial (NCT01631552) of 108 subjects with mTNBC who had received at least two prior treatments for metastatic disease. This study demonstrated an objective response rate (ORR) of $33.3 \%$ and a median duration of response (DOR) of 7.7 months after receiving sacituzumab govitecan at a fractional dose of 10 $\mathrm{mg} / \mathrm{kg}$ once weekly on Days 1 and 8 of continuous 21-day treatment cycles [68].

The FDA has granted breakthrough therapy designation to sacituzumab govitecan for mTNBC, fast track designation for mTNBC, locally advanced, or metastatic urothelial cancer (UC), metastatic NSCLC, and small-cell lung cancer (SCLC), as well as orphan drug designation for SCLC and pancreatic cancer [67]. It is currently being evaluated in several clinical trials on various epithelial tumors, as summarized in Table 2.

Table 2. Sacituzumab govitecan clinical trials with reported results.

\begin{tabular}{|c|c|c|c|c|c|c|c|c|c|}
\hline \multirow{2}{*}{$\begin{array}{l}\text { NCT } \\
\text { Identifier }\end{array}$} & \multirow[t]{2}{*}{$\mathbf{P h}$} & \multirow[t]{2}{*}{ Indication } & \multicolumn{6}{|c|}{ Clinical Response } & \multirow[t]{2}{*}{ Ref } \\
\hline & & & $\mathbf{N}$ & ORR & DOR & CBR & PFS & OS & \\
\hline \multirow[t]{6}{*}{ NCT01631552 } & I & $\begin{array}{l}\text { Epithelial } \\
\text { tumors }\end{array}$ & 25 & $\begin{array}{l}\text { 8\% (2PR: } \\
\text { TNBC, } \\
\text { colon } \\
\text { cancer) }\end{array}$ & - & - & - & - & [69] \\
\hline & \multirow[t]{5}{*}{ II } & TNBC* & 108 & $\begin{array}{l}33.3 \% \\
(3 \mathrm{CR} / 33 \mathrm{PR})\end{array}$ & $7.7 \mathrm{~m}$ & $45.4 \%$ & $5.5 \mathrm{~m}$ & $13 \mathrm{~m}$ & [68] \\
\hline & & NSCLC & 54 & $19 \%$ (9PR) & $6.0 \mathrm{~m}$ & $43 \%$ & $5.2 \mathrm{~m}$ & $9.5 \mathrm{~m}$ & {$[72]$} \\
\hline & & SCLC & 50 & $14 \%$ (7PR) & $5.7 \mathrm{~m}$ & $34 \%$ & $3.7 \mathrm{~m}$ & $7.5 \mathrm{~m}$ & [73] \\
\hline & & $\mathrm{UC}$ & 45 & $\begin{array}{l}31 \% \\
(2 \mathrm{CR} / 12 \mathrm{PR})\end{array}$ & $12.6 \mathrm{~m}$ & $47 \%$ & $7.3 \mathrm{~m}$ & $18.9 \mathrm{~m}$ & [74] \\
\hline & & $\begin{array}{l}\mathrm{HR}+/ \mathrm{HER} 2- \\
\mathrm{BC}\end{array}$ & 54 & $31 \%(17 \mathrm{PR})$ & $7.4 \mathrm{~m}$ & $48 \%$ & - & - & {$[71,110]$} \\
\hline \multirow[t]{2}{*}{ NCT03547973 } & \multirow[t]{2}{*}{ II } & $\begin{array}{l}\text { UC } \\
\text { (progressed } \\
\text { after } \\
\text { platinum- } \\
\text { based } \\
\text { regimen and } \\
\text { CPI therapy) }\end{array}$ & 35 & $\begin{array}{l}29 \%(2 \\
\text { confirmed } \\
\text { CR/ } 5 \\
\text { confirmed } \\
\text { PR/ } 3 \\
\text { unconfirmed } \\
\text { PR) }\end{array}$ & - & - & - & - & [76] \\
\hline & & $\begin{array}{l}\text { UC } \\
\text { (ineligible } \\
\text { for platinum- }\end{array}$ & 18 & $\begin{array}{l}28 \%(4 \\
\text { confirmed } \\
\text { PR/ } 1\end{array}$ & - & - & - & - & {$[77]$} \\
\hline
\end{tabular}




\begin{tabular}{|c|c|c|c|c|c|c|c|c|}
\hline & $\begin{array}{l}\text { based } \\
\text { therapy and } \\
\text { progressed } \\
\text { after CPI } \\
\text { therapy) }\end{array}$ & & $\begin{array}{l}\text { unconfirmed } \\
\text { PR) }\end{array}$ & & & & & \\
\hline NCT03992131 I/II & $\begin{array}{l}\text { Solid tumors } \\
\text { (in } \\
\text { combination } \\
\text { with } \\
\text { Rucaparib }\end{array}$ & 6 & $\begin{array}{l}50 \%(3 \\
\text { confirmed } \\
\mathrm{PR})\end{array}$ & - & - & - & - & $\begin{array}{l}\text { ESMO2020 } \\
\text { Poster: } 547 \mathrm{P}\end{array}$ \\
\hline NCT03995706 & $\begin{array}{l}\text { TNBC brain } \\
\text { metastasis/ } \\
\text { Glioblastoma }\end{array}$ & 14 & $29 \%$ (4PR) & - & - & - & - & $\begin{array}{c}\text { ESMO2020 } \\
\text { Presentation: } \\
\text { 373MO }\end{array}$ \\
\hline \multicolumn{9}{|c|}{$\begin{array}{l}\text { TNBC, triple-negative breast cancer; NSCLC, non-small cell lung cancer; SCLC, small cell lung cancer; UC, } \\
\text { urothelial cancer; HR+/HER2- BC, hormone receptor-positive/human epidermal growth factor receptor 2- } \\
\text { negative breast cancer; ORR, objective response rate; DOR, duration of response; CBR, clinical benefit rate; } \\
\text { PFS, progression-free survival; OS, overall survival; CR, complete response; PR, partial response; m, } \\
\text { month } \\
\text { *Approval in the US for the treatment of adult patients with metastatic TNBC who have received at least two } \\
\text { prior therapies for metastatic disease. }\end{array}$} \\
\hline
\end{tabular}

In a Phase I first-in-human clinical trial (NCT01631552; IMMU-132-01) in patients with diverse metastatic solid tumors, sacituzumab govitecan exhibited acceptable toxicity and encouraging antitumor activity in those patients with difficult-to-treat cancers [69]. Of 25 treated patients, two patients (TNBC and colon cancer) achieved PRs, and 16 had stable disease. The maximum tolerated dose was $12 \mathrm{mg} / \mathrm{kg}$ (fractional dose, 2 administrations one week apart within each 3 -week dosing cycle). The 8 and $10 \mathrm{mg} / \mathrm{kg}$ dosage levels had acceptable tolerability profile and were subsequently selected for phase II studies.

In the Phase II dose-expansion portion of the IMMU-132-01 trial, the therapeutic effect of sacituzumab govitecan was evaluated in 4 cancer subtypes (TNBC, NSCLC, SCLC, UC) and other cancer types [70]. One hundred eight patients with TNBC who had received a median of 3 previous therapies achieved durable objective responses with an ORR ( 3 complete and 33 partial responses) of $33.3 \%$, a median progression-free survival (PFS) of 5.5 months, and overall survival (OS) of 13.0 months [68]. Moreover, 54 patients with hormone receptorpositive $(\mathrm{HR}+)$ /human epidermal growth factor receptor 2-negative (HER2-) breast cancer (BC) received at least 2 prior therapies, including treatments in any setting of taxane $(93 \%)$, anthracycline (69\%), and cyclin-dependent kinase (CDK) 4/6 inhibitors (69\%). The ORR of those patients was $31 \%$ [71]. In the response-assessable study population $(n=47)$ of NSCLC, the ORR was $19 \%$. In comparison, the ORR in the intention-to-treat (ITT) population $(\mathrm{n}=54)$, including patients who had relapsed or progressed after immune checkpoint inhibitor (CPI) treatment, was $17 \%$, and the median ITT OS was 9.5 months [72]. In the ITT population of SCLC $(\mathrm{n}=50)$, the ORR was $14 \%$, the median PFS was 3.7 months, and the median OS was 7.5 months [73]. Also, 45 patients with urothelial cancer who received a median of 2 prior treatment lines, including platinum-based chemotherapy (95\%) and CPI therapy (38\%), demonstrated an ORR of $31 \%$ with 2 CRs and 12 PRs. In particular, the ORR in patients with visceral involvement and in patients treated with CPI was $27 \%(9 / 33)$ and $23 \%(4 / 17)$. The median PFS and OS were 7.3 months and 18.9 months, respectively [74]. A global, open-label, Phase II study (NCT03547973; TROPHY U-01) is underway to evaluate the antitumor activity and safety of sacituzumab govitecan in patients with metastatic urothelial cancer [75]. A preplanned interim analysis was perform based on data from Cohort 1 (patients who progressed after platinum-based regimen and CPI therapy) and Cohort 2 (patients who were ineligible for platinum-based therapy and progressed after CPI therapy in the first-line setting). 35 patients 
from Cohort 1 had an ORR of 29\% with 2 confirmed CRs, 5 established PRs and 3 unconfirmed PRs, meanwhile, 74\% (26/35) of patients had target lesion reduction [76]. On the other hand, over $60 \%$ of the patients $(11 / 18)$ in Cohort 2 had target lesion reduction, and the ORR was $28 \%$ with 4 confirmed PRs, and 1 PR pending confirmation [77]. The encouraging early-stage clinical results of sacituzumab govitecan in breast cancer brain metastasis and glioblastoma showing 4 of 17 patients achieved PRs also suggest its potential in treating brain cancer (ESMO2020; Presentation: 373MO).

Two confirmatory multicenter, randomized, Phase III trials compared sacituzumab govitecan versus the physician's choice in patients with metastatic TNBC (NCT02574455; ASCENT) and HR+/HER2- BC (NCT03901339; TROPICS-02) were subsequently launched [78]. The ASCENT trial was stopped earlier than planned upon recommendation of an independent Data Safety Monitoring Committee due to compelling evidence of efficacy [67]. Sacituzumab govitecan achieved a significant improvement in the PFS compared to chemotherapy, with a hazard ratio of 0.41 and a median PFS of 5.6 months, compared to 1.7 months for chemotherapy.

With the knowledge that Trop 2 is highly expressed in various solid cancers, the expression of Trop 2 was not designed as a preselection criterion in clinical trials with sacituzumab govitecan. Indeed, the retrospective clinical data revealed that more than $80 \%$ of archived tumor samples had high staining of Trop 2. The results did not fully support Trop 2 to be a predictive biomarker for response; however, a greater response was observed in patients with high expression of TROP-2 in their tumors [24,72,73]. By using a less-stable innovative CL2A linker, that is accessible by extracellular proteases with low pH sensitivity, SN-38 is believed to be accessible to tumor cells in the immediate environment and exert "bystander effect" by targeting not only the cells directly targeted by sacituzumab govitecan [70]. The anti-tumor cytotoxic effects of this dual release mechanism through internalization and immediate release on both Trop 2 positive and Trop 2 negative tumor cells, makes this ADC less dependable on high expression of Trop 2 on the targeted tumors. Apart from that, the heterogeneous expression of Trop 2, in terms of the percentage of cells expressing the antigen and their distribution in the tumor, as well as the diversity in the sensitivity to SN-38 will all likely govern the response of sacituzumab govitecan.

The expression of Trop 2 in several normal tissues, although appearing to be lower than in cancers, raises concerns on the specificity and potential for toxicities in non-cancerous healthy tissues. However, the evidence from toxicological studies in monkeys, where despite escalating doses of sacituzumab govitecan produced only off-target SN-38 associated toxicities, including neutropenia and diarrhea, suggest no major significant histopathological changes in the majority of Trop 2 expressing normal tissues (e.g., skin, trachea, pancreas, kidneys, cervix, and uterus) [79]. In clinical trials, no significant Trop 2 expression mediated toxicities were observed; however, the sacituzumab govitecan produced severe neutropenia, severe diarrhea, severe vomiting and nausea (FDA Blackbox Warning). One important feature of this ADC is that following administration, more than $90 \%$ of SN-38 is released from the ADC within 3 days, and the free SN-38 was cleared rapidly, attenuating the off-target toxicity [70].

The major toxicities of irinotecan, the parent molecule of SN38 are mainly neutropenia and diarrhea. SN-38 is a semi-synthetic camptothecin which is the active component of irinotecan. After irinotecan administration, $\mathrm{SN}-38$ is eliminated rapidly by the liver into the intestinal tract as the inactive SN-38 glucuronide (SN-38G) form, while SN-38G recirculates by the enterohepatic circulation, delaying its elimination, but eventually, bacteria in the intestine convert SN-38G to SN-38, resulting in "late" diarrhea [80]. In clinical trials with sacituzumab govitecan, neutropenia was the main cause of dose delays or reduction. However, the percentage of diarrhea, precisely grade 3 or 4 diarrhea in patients given $10 \mathrm{mg} / \mathrm{kg}$, was much lower than that of irinotecan therapy, most likely because of the very low SN-38G level in the 
serum after sacituzumab govitecan administration where $\mathrm{SN}-38$ bound to IgG is largely protected from glucuronidation.

\subsubsection{DS- 1062}

DS-1062 (datopotamab deruxtecan) is comprised of a humanized anti-Trop 2 monoclonal antibody attached to a novel DNA topoisomerase I inhibitor, exatecan derivative (DXd) by a tetrapeptide-based linker, as the payload with a DAR of 4.[81] A Phase I, open-label, multipledose, first-in-human study (NCT03401385) of DS-1062 in patients with advanced solid tumors is currently ongoing to evaluate the safety, tolerability, and efficacy in NSCLC and/or TNBC participants [82]. Up to November 2019, 95 patients had received more than one dose of DS1062, and 22 patients of the 88 response-evaluable patients achieved PR [83]. The estimated primary completion date is January 1, 2022. Another Phase II trial (NCT04484142) in patients with advanced or metastatic NSCLC with actionable genomic alterations had recently been initiated to determine the efficacy of 2 doses of DS-1062 (6mg/ $/ \mathrm{kg}$ and $8 \mathrm{mg} / \mathrm{kg}$, every 3 weeks) in those patients. The most recent DS-1062 efficacy data in NSCLC patients showed a $27 \%$ $(23 / 85)$ ORR in unselected Trop 2 expression and in last line therapy (post platinum and checkpoint inhibitor) NSCLC patients; sustained durable responses were observed in 23 NSCLC patients with three patients lasting beyond 12 months (the virtual 2020 ASCO Annual Meeting in May). It is important to note that data also pointed out for a potential critical safety issue that requires attention. Overall, there was eight $(5.8 \%)$ occurrences of drug-related interstitial lung disease with two deemed grade 5, one grade 3, and four Grade 2.

\subsubsection{Other anti-Trop 2 ADCs}

Several other anti-Trop 2 ADC products, such as BAT8003 and SKB264, have entered the clinical trial stage. BAT8003, an ADC containing an uncleavable linker and a maytansine derivative as the payload, had been shown to be effectively internalized upon binding to Trop 2 , and to inhibit proliferation and tumor growth in both in vitro and in vivo models [84]. BAT8003 was designed to possess enhanced ADCC effects through afucosylation of the antibody, compared with sacituzumab govitecan lost as much as $60 \%$ of ADCC after conjugation [85]. A Phase I trial (NCT03884517) is undergoing to evaluate the safety, tolerability and pharmacokinetics of BAT 8003 as a single agent in subjects with Trop 2 positive cancers. SKB264 is an optimized Trop 2-targeting ADC with a belotecan-derived payload and currently being evaluated in Phase I/II study (NCT04152499) where the safety, efficacy, and clinical activity of SKB264 as a mono-therapeutic agent will be determined in specified tumor types, including ovarian epithelial cancer, gastric adenocarcinoma, pancreatic adenocarcinoma, TNBC and bladder cancer [86].

\subsection{Anti-Trop 2 cell therapy}

Several Trop 2-targeting chimeric antigen receptor-T (CAR-T) cells have presented their activities against various epithelial tumor cell lines, such as breast, prostate, and pancreatic tumor cells. However, these CAR-T cells unavoidably caused the "off-target" effect by killing Trop 2 negative cells in the presence of Trop 2 positive cells as activated CAR-T cells induced cell apoptosis through death receptors [87]. To overcome the high heterogeneity and complex tumor microenvironment in solid tumors and abolish the non-specific cytotoxicity, a novel bispecific Trop 2/programmed death-ligand 1 (PD-L1) CAR-T have recently been developed and shown enhanced tumor-killing effect on gastric cancer cells over monospecific CAR-T cells (Trop 2 CAR-T and PD-L1 CAR-T) [88]. Due to the baseline expression of Trop 2 in normal tissues, further studies are warranted to compare the antitumor effects of those CAR-T cells towards cells with different expression levels of the Trop 2 antigen. 
On the other hand, a Trop 2-targeting "dual-gate" CAR-T strategy is being deployed to enhance the specificity and alleviate potential "off-tumor" toxicity of carcinoembryonic antigen-related cell adhesion molecule 5 (CEACAM5) CARs in neuroendocrine prostate cancer (NEPC) [89]. CEACAM5 is highly expressed in a broad range of tumors, including those of the gastrointestinal tract and NEPC, and thus has been extensively explored as a therapeutic target [90]. However, results from the clinical trial on the first-generation CEACAM5-specific CAR T cells were disappointed with unfavorable "on-target, off-tumor" toxicity [91]. As Trop 2 is overexpressed in NEPC with limited nonoverlapping expressions with CEACAM5 in normal tissues, a "dual-gate" CAR-T is equipped with Trop 2 targeted CAR in addition to CEACAM5 targeted CAR is being explored to mitigate the toxicity $[92,93]$.

\subsection{Combination therapy}

Trop 2 targeted therapy as part of combination therapy appears promising for the treatment of various solid tumors. A potential advantage of concurrent administration is to maximize synergistic interactions between the two or more therapies; however, toxicities of combination therapies must be carefully evaluated. The combinations of Trop 2 targeted and other therapeutics have been demonstrated to be a rational and pursuable strategy in many ways. For example, it is reported that cisplatin-induced Trop 2 surface expression in human lung cancer cells meanwhile Trop 2 inhibition could reverse the chemotherapy-induced immuno-resistance via interaction with MAPK pathway, implicating potential benefits of combining Trop 2 targeted therapeutics with chemotherapy [94]. Because Trop 2 is a potent predictor of tumor response to AKT inhibitors, Trop 2 targeted approaches may be a useful partner for AKTdependent tumors [95]. Given the clinical benefit of sacituzumab govitecan, several combination strategies with Trop 2 ADC have been investigated. Members of the ATP-binding cassette $(\mathrm{ABC})$ transporters are a frequent cause of chemotherapy resistance by active drug efflux. ABCG2 inhibitors were able to restore the tumor sensitivity to SN-38, meanwhile the combination of an ABCG2 inhibitor and sacituzumab govitecan significantly improved survival in mice bearing SN-38 resistant tumors [96].

Over the past two decades, advances have been achieved in cancer treatment with the development of targeted therapies that work on blocking the drivers of tumorigenesis as well as with recent immunomodulatory therapies that enhance a patient's antitumor immunity. Targeted therapies produce profound but transient clinical responses in corresponding tumor types, whereas tumor escape and relapse tend to arise over time after an initial response. On the contrary, immunotherapies can elicit durable responses across multiple tumor types. The idea of combining the targeted therapy with immunotherapy has led to a surge of research and clinical development, aiming to deliver a complete and durable clinical response in cancer patients. As to Trop 2 ADC, the combinations of sacituzumab govitecan with anti-PD-1/PDL1 immunotherapies are being evaluated for the efficacy and safety in patients with TNBC (NCT03424005) and urothelial cancer (NCT03547973). Meanwhile, the safety and treatment activity of DS-1062 in combination with pembrolizumab is also been assessed in participants with advanced or metastatic NSCLC without actionable genomic alterations who have had previously treated with platinum-based therapy with or without prior immunotherapy (NCT04526691). One of the advantages of this combination is that both DS-1062 and Pembrolizumab are given every 3 weeks on Day 1 of each 21 -day cycle.

Sacituzumab govitecan combined with various poly (ADP-ribose) polymerase (PARP) produced additive and synergistic effects on antitumor activities and tumor suppression compared with monotherapy in mice bearing xenografts of TNBC, regardless of BRCA1/2 status [97]. Their combinations are currently being examined clinically in solid tumors (NCT04039230; NCT03992131). In ESMO 2020, Yap et al. reported the initial data from the SEASTAR study evaluating the safety and preliminary efficacy of the combination of 
sacituzumab govitecan and rucaparib in patients with solid tumors (ESMO 2020; Poster number: 547P). Five of 6 patients experienced grade $3 / 4$ neutropenia but were able to continue treatment for at least 12 weeks; three patients, diagnosed with TNBC, serous ovarian cancer and endometrial cancer respectively, had confirmed PR, while the other 3 patients achieved SD. Further evaluation of the combination is warranted.

Given the multitude of signaling pathways Trop 2 is involved in, rational targets should be explored to facilitate the combination of Trop 2 targeted therapeutics with other antitumor agents.

\section{Summary}

The selection of right targets is crucial but challenging for targeted therapy. The key challenges for ADC development are summarized in Table 3. The rationale of Trop 2 as a desired therapeutic target is principally based on the following characteristics: 1) Trop 2 is a oncogenic antigen overexpressed across various solid tumors with limited expression and homeostasis roles in normal tissues; 2) preclinical in vivo models, completed and ongoing clinical trials have demonstrated a robust antitumor activities and favorable therapeutic indexes with Trop 2 targeted therapy (Table 4). The complexity of Trop 2 structure and function makes the development of small molecule inhibitors highly challenging. On the other hand, unarmed antiTrop $2 \mathrm{mAbs}$ have not because of their abilities to deliver antitumor cytotoxic warheads have demonstrated meaningful treatment benefits. Trop 2 ADCs prove to be effective in the treatment of an expanding list of solid tumors, and they are actively being evaluated in combination with other cancer therapies. Future product development in this field may involve bi-specific mAbs and ADCs, cell therapies, rational therapeutic combinations and novel drugdelivery modalities.

\section{Table 3. The key challenges for ADC development.}

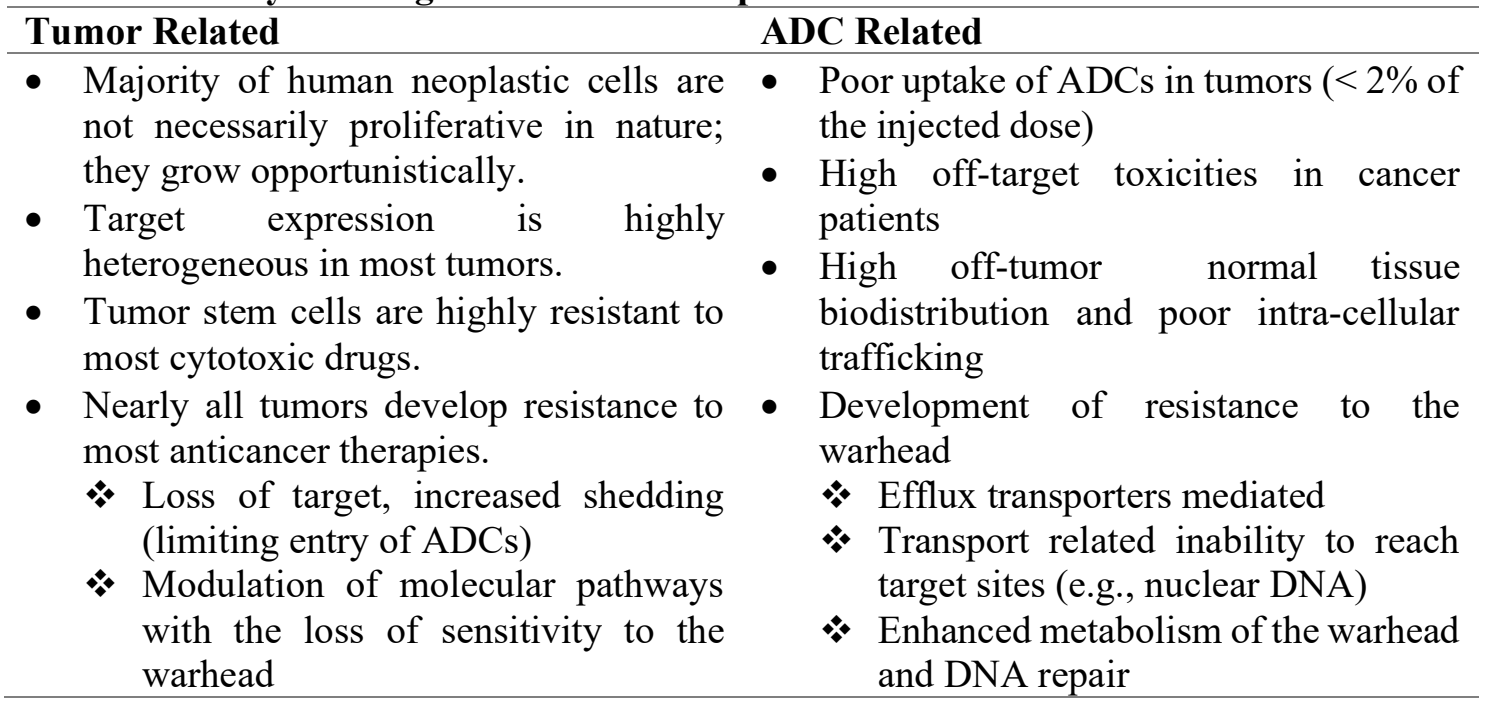


Table 4. Comparisons of different Trop 2 targeted modalities.

\begin{tabular}{|c|c|c|c|c|}
\hline $\begin{array}{l}\text { Trop } 2 \text { targeted } \\
\text { modalities }\end{array}$ & Pros & Cons & $\begin{array}{l}\text { Development } \\
\text { stage }\end{array}$ & Promises \\
\hline $\begin{array}{l}\text { Small molecule } \\
\text { inhibitor }\end{array}$ & $\begin{array}{l}\text { Intracellular target; oral } \\
\text { availability }\end{array}$ & $\begin{array}{l}\text { Require direct inhibition } \\
\text { of the functional activity } \\
\text { of the target protein and } \\
\text { suitable binding pockets; } \\
\text { high systemic drug } \\
\text { exposures to achieve } \\
\text { occupation }\end{array}$ & Unavailable & No \\
\hline $\begin{array}{l}\text { Monospecific } \\
\text { antibody }\end{array}$ & $\begin{array}{l}\text { High binding affinity } \\
\text { and specificity; } \\
\text { prolonged PK profile; } \\
\text { allow protein-protein } \\
\text { interaction }\end{array}$ & $\begin{array}{l}\text { Cannot cross the } \\
\text { membrane; need } \\
\text { parenteral delivery }\end{array}$ & Preclinical & Yes \\
\hline Bispecific antibody & $\begin{array}{l}\text { Allowing binding to two } \\
\text { separate antigens or } \\
\text { epitopes; high target } \\
\text { specificity and } \\
\text { therapeutic potency }\end{array}$ & $\begin{array}{l}\text { Depending on engaging } \\
\text { the body's immune } \\
\text { system; cytokine release } \\
\text { syndrome; need parenteral } \\
\text { delivery }\end{array}$ & Preclinical & Yes \\
\hline ADC & $\begin{array}{l}\text { High specificity; wide } \\
\text { therapeutic window; } \\
\text { slow drug resistance }\end{array}$ & $\begin{array}{l}\text { Unpredictable toxicity; } \\
\text { need parenteral delivery }\end{array}$ & Clinical & Yes \\
\hline T Cell therapy & $\begin{array}{l}\text { Prolonged effective } \\
\text { period ("living drug") }\end{array}$ & $\begin{array}{l}\text { Depending on engaging } \\
\text { the body's immune } \\
\text { system; cytokine release } \\
\text { syndrome; high cost }\end{array}$ & Preclinical & Yes \\
\hline
\end{tabular}

Author Contributions: Conceptualization, S.L. and X.X.; writing - original draft preparation, S.L.; writing - review and editing, B.W., R.Z., H.B., X.C. and R.D. All authors have read and agreed to the published version of the manuscript.

Funding: This research received no external funding.

Conflicts of Interest: The authors declare that they have no conflict of interest with the contents of this review.

\section{References}

1. Lipinski, M.; Parks, D.R.; Rouse, R.V.; Herzenberg, L.A. Human trophoblast cellsurface antigens defined by monoclonal antibodies. Proc Natl Acad Sci U S A 1981, 78, 5147-5150, doi:10.1073/pnas.78.8.5147.

2. Cubas, R.; Li, M.; Chen, C.; Yao, Q. Trop2: a possible therapeutic target for late stage epithelial carcinomas. Biochim Biophys Acta 2009, 1796, 309-314, doi:10.1016/j.bbcan.2009.08.001.

3. Shvartsur, A.; Bonavida, B. Trop2 and its overexpression in cancers: regulation and clinical/therapeutic implications. Genes Cancer 2015, 6, 84-105, doi:10.18632/genesandcancer.40.

4. Zeng, P.; Chen, M.B.; Zhou, L.N.; Tang, M.; Liu, C.Y.; Lu, P.H. Impact of TROP2 expression on prognosis in solid tumors: A Systematic Review and Meta-analysis. Sci Rep 2016, 6, 33658, doi:10.1038/srep33658. 
5. McDougall, A.R.; Tolcos, M.; Hooper, S.B.; Cole, T.J.; Wallace, M.J. Trop2: from development to disease. Dev Dyn 2015, 244, 99-109, doi:10.1002/dvdy.24242.

6. Mihelic, M.; Turk, D. Two decades of thyroglobulin type-1 domain research. Biol Chem 2007, 388, 1123-1130, doi:10.1515/bc.2007.155.

7. Lin, J.C.; Wu, Y.Y.; Wu, J.Y.; Lin, T.C.; Wu, C.T.; Chang, Y.L.; Jou, Y.S.; Hong, T.M.; Yang, P.C. TROP2 is epigenetically inactivated and modulates IGF-1R signalling in lung adenocarcinoma. EMBO Mol Med 2012, 4, 472-485, doi:10.1002/emmm.201200222.

8. El Sewedy, T.; Fornaro, M.; Alberti, S. Cloning of the murine TROP2 gene: conservation of a PIP2-binding sequence in the cytoplasmic domain of TROP-2. Int $J$ Cancer 1998, 75, 324-330, doi:10.1002/(sici)1097-0215(19980119)75:2<324::aidijc24>3.0.co;2-b.

9. Basu, A.; Goldenberg, D.M.; Stein, R. The epithelial/carcinoma antigen EGP-1, recognized by monoclonal antibody RS7-3G11, is phosphorylated on serine 303 . Int $J$ Cancer 1995, 62, 472-479, doi:10.1002/ijc.2910620419.

10. Ciccarelli, F.D.; Acciarito, A.; Alberti, S. Large and diverse numbers of human diseases with HIKE mutations. Hum Mol Genet 2000, 9, 1001-1007, doi:10.1093/hmg/9.6.1001.

11. Goldenberg, D.M.; Stein, R.; Sharkey, R.M. The emergence of trophoblast cell-surface antigen 2 (TROP-2) as a novel cancer target. Oncotarget 2018, 9, 28989-29006, doi:10.18632/oncotarget.25615.

12. Stepan, L.P.; Trueblood, E.S.; Hale, K.; Babcook, J.; Borges, L.; Sutherland, C.L. Expression of Trop2 cell surface glycoprotein in normal and tumor tissues: potential implications as a cancer therapeutic target. J Histochem Cytochem 2011, 59, 701-710, doi:10.1369/0022155411410430.

13. Trerotola, M.; Cantanelli, P.; Guerra, E.; Tripaldi, R.; Aloisi, A.L.; Bonasera, V.; Lattanzio, R.; de Lange, R.; Weidle, U.H.; Piantelli, M., et al. Upregulation of Trop-2 quantitatively stimulates human cancer growth. Oncogene 2013, 32, 222-233, doi:10.1038/onc.2012.36.

14. Liu, T.; Liu, Y.; Bao, X.; Tian, J.; Liu, Y.; Yang, X. Overexpression of TROP2 predicts poor prognosis of patients with cervical cancer and promotes the proliferation and invasion of cervical cancer cells by regulating ERK signaling pathway. PLoS One 2013, 8, e75864, doi:10.1371/journal.pone.0075864.

15. Ning, S.; Guo, S.; Xie, J.; Xu, Y.; Lu, X.; Chen, Y. TROP2 correlates with microvessel density and poor prognosis in hilar cholangiocarcinoma. J Gastrointest Surg 2013, 17, 360-368, doi:10.1007/s11605-012-2105-1.

16. Fong, D.; Moser, P.; Krammel, C.; Gostner, J.M.; Margreiter, R.; Mitterer, M.; Gastl, G.; Spizzo, G. High expression of TROP2 correlates with poor prognosis in pancreatic cancer. Br J Cancer 2008, 99, 1290-1295, doi:10.1038/sj.bjc.6604677.

17. Tang, G.; Tang, Q.; Jia, L.; Xia, S.; Li, J.; Chen, Y.; Li, H.; Ding, X.; Wang, F.; Hou, D., et al. High expression of TROP2 is correlated with poor prognosis of oral squamous cell carcinoma. Pathol Res Pract 2018, 214, 1606-1612, doi:10.1016/j.prp.2018.07.017.

18. Zhao, W.; Zhu, H.; Zhang, S.; Yong, H.; Wang, W.; Zhou, Y.; Wang, B.; Wen, J.; Qiu, Z.; Ding, G., et al. Trop2 is overexpressed in gastric cancer and predicts poor prognosis. Oncotarget 2016, 7, 6136-6145, doi:10.18632/oncotarget.6733.

19. Fang, Y.J.; Lu, Z.H.; Wang, G.Q.; Pan, Z.Z.; Zhou, Z.W.; Yun, J.P.; Zhang, M.F.; Wan, D.S. Elevated expressions of MMP7, TROP2, and survivin are associated with survival, disease recurrence, and liver metastasis of colon cancer. Int J Colorectal Dis 2009, 24, 875-884, doi:10.1007/s00384-009-0725-z. 
20. Bignotti, E.; Todeschini, P.; Calza, S.; Falchetti, M.; Ravanini, M.; Tassi, R.A.; Ravaggi, A.; Bandiera, E.; Romani, C.; Zanotti, L., et al. Trop-2 overexpression as an independent marker for poor overall survival in ovarian carcinoma patients. Eur $J$ Cancer 2010, 46, 944-953, doi:10.1016/j.ejca.2009.12.019.

21. Bignotti, E.; Zanotti, L.; Calza, S.; Falchetti, M.; Lonardi, S.; Ravaggi, A.; Romani, C.; Todeschini, P.; Bandiera, E.; Tassi, R.A., et al. Trop-2 protein overexpression is an independent marker for predicting disease recurrence in endometrioid endometrial carcinoma. BMC Clin Pathol 2012, 12, 22, doi:10.1186/1472-6890-12-22.

22. Pak, M.G.; Shin, D.H.; Lee, C.H.; Lee, M.K. Significance of EpCAM and TROP2 expression in non-small cell lung cancer. World J Surg Oncol 2012, 10, 53, doi:10.1186/1477-7819-10-53.

23. Ambrogi, F.; Fornili, M.; Boracchi, P.; Trerotola, M.; Relli, V.; Simeone, P.; La Sorda, R.; Lattanzio, R.; Querzoli, P.; Pedriali, M., et al. Trop-2 is a determinant of breast cancer survival. PLoS One 2014, 9, e96993, doi:10.1371/journal.pone.0096993.

24. Bardia, A.; Mayer, I.A.; Diamond, J.R.; Moroose, R.L.; Isakoff, S.J.; Starodub, A.N.; Shah, N.C.; O'Shaughnessy, J.; Kalinsky, K.; Guarino, M., et al. Efficacy and Safety of Anti-Trop-2 Antibody Drug Conjugate Sacituzumab Govitecan (IMMU-132) in Heavily Pretreated Patients With Metastatic Triple-Negative Breast Cancer. J Clin Oncol 2017, 35, 2141-2148, doi:10.1200/jco.2016.70.8297.

25. Zhao, W.; Kuai, X.; Zhou, X.; Jia, L.; Wang, J.; Yang, X.; Tian, Z.; Wang, X.; Lv, Q.; Wang, B., et al. Trop2 is a potential biomarker for the promotion of EMT in human breast cancer. Oncol Rep 2018, 40, 759-766, doi:10.3892/or.2018.6496.

26. Lin, H.; Huang, J.F.; Qiu, J.R.; Zhang, H.L.; Tang, X.J.; Li, H.; Wang, C.J.; Wang, Z.C.; Feng, Z.Q.; Zhu, J. Significantly upregulated TACSTD2 and Cyclin D1 correlate with poor prognosis of invasive ductal breast cancer. Exp Mol Pathol 2013, 94, 73-78, doi:10.1016/j.yexmp.2012.08.004.

27. Guo, X.; Zhu, X.; Zhao, L.; Li, X.; Cheng, D.; Feng, K. Tumor-associated calcium signal transducer 2 regulates neovascularization of non-small-cell lung cancer via activating ERK1/2 signaling pathway. Tumour Biol 2017, 39, 1010428317694324, doi:10.1177/1010428317694324.

28. Li, Z.; Jiang, X.; Zhang, W. TROP2 overexpression promotes proliferation and invasion of lung adenocarcinoma cells. Biochem Biophys Res Commun 2016, 470, 197 204, doi:10.1016/j.bbrc.2016.01.032.

29. Omori, S.; Kenmotsu, H.; Muramatsu, K.; Kawata, T.; Kobayashi, H.; Nakashima, K.; Wakuda, K.; Ono, A.; Naito, T.; Murakami, H., et al. Changes in TROP2 expression in lung cancer patients receiving anticancer treatments. 2019, 37, e14732-e14732, doi:10.1200/JCO.2019.37.15 suppl.e14732.

30. Inamura, K.; Yokouchi, Y.; Kobayashi, M.; Ninomiya, H.; Sakakibara, R.; Subat, S.; Nagano, H.; Nomura, K.; Okumura, S.; Shibutani, T., et al. Association of tumor TROP2 expression with prognosis varies among lung cancer subtypes. Oncotarget 2017, 8, 28725-28735, doi:10.18632/oncotarget.15647.

31. Jiang, A.; Gao, X.; Zhang, D.; Zhang, L.; Lu, H. Expression and clinical significance of the Trop-2 gene in advanced non-small cell lung carcinoma. Oncol Lett 2013, 6, 375380, doi:10.3892/ol.2013.1368.

32. Piechowski, J. Plausibility of trophoblastic-like regulation of cancer tissue. Cancer Manag Res 2019, 11, 5033-5046, doi:10.2147/cmar.S190932.

33. Ripani, E.; Sacchetti, A.; Corda, D.; Alberti, S. Human Trop-2 is a tumor-associated calcium signal transducer. Int $J$ Cancer 1998, 76, 671-676, doi:10.1002/(sici)10970215(19980529)76:5<671::aid-ijc10>3.0.co;2-7. 
34. Trerotola, M.; Li, J.; Alberti, S.; Languino, L.R. Trop-2 inhibits prostate cancer cell adhesion to fibronectin through the $\beta 1$ integrin-RACK1 axis. J Cell Physiol 2012, 227, 3670-3677, doi:10.1002/jcp.24074.

35. Guerra, E.; Trerotola, M.; Aloisi, A.L.; Tripaldi, R.; Vacca, G.; La Sorda, R.; Lattanzio, R.; Piantelli, M.; Alberti, S. The Trop-2 signalling network in cancer growth. Oncogene 2013, 32, 1594-1600, doi:10.1038/onc.2012.151.

36. Zhao, W.; Jia, L.; Kuai, X.; Tang, Q.; Huang, X.; Yang, T.; Qiu, Z.; Zhu, J.; Huang, J.; Huang, W., et al. The role and molecular mechanism of Trop2 induced epithelialmesenchymal transition through mediated $\beta$-catenin in gastric cancer. Cancer Med 2019, 8, 1135-1147, doi:10.1002/cam4.1934.

37. Zaman, S.; Jadid, H.; Denson, A.C.; Gray, J.E. Targeting Trop-2 in solid tumors: future prospects. Onco Targets Ther 2019, 12, 1781-1790, doi:10.2147/ott.S162447.

38. Trerotola, M.; Jernigan, D.L.; Liu, Q.; Siddiqui, J.; Fatatis, A.; Languino, L.R. Trop-2 promotes prostate cancer metastasis by modulating $\beta(1)$ integrin functions. Cancer Res 2013, 73, 3155-3167, doi:10.1158/0008-5472.Can-12-3266.

39. Solimini, N.L.; Luo, J.; Elledge, S.J. Non-oncogene addiction and the stress phenotype of cancer cells. Cell 2007, 130, 986-988, doi:10.1016/j.cell.2007.09.007.

40. Kaae, J.; Wohlfahrt, J.; Boyd, H.A.; Wulf, H.C.; Biggar, R.J.; Melbye, M. The impact of autoimmune diseases on the incidence and prognosis of cutaneous malignant melanoma. Cancer Epidemiol Biomarkers Prev 2007, 16, 1840-1844, doi:10.1158/1055-9965.Epi-07-0459.

41. Zaenker, P.; Gray, E.S.; Ziman, M.R. Autoantibody Production in Cancer--The Humoral Immune Response toward Autologous Antigens in Cancer Patients. Autoimmun Rev 2016, 15, 477-483, doi:10.1016/j.autrev.2016.01.017.

42. Nakashima, K.; Shimada, H.; Ochiai, T.; Kuboshima, M.; Kuroiwa, N.; Okazumi, S.; Matsubara, H.; Nomura, F.; Takiguchi, M.; Hiwasa, T. Serological identification of TROP2 by recombinant cDNA expression cloning using sera of patients with esophageal squamous cell carcinoma. Int $J$ Cancer 2004, 112, 1029-1035, doi:10.1002/ijc.20517.

43. Mangino, G.; Grazia Capri, M.; Barnaba, V.; Alberti, S. Presentation of native TROP2 tumor antigens to human cytotoxic $\mathrm{T}$ lymphocytes by engineered antigen-presenting cells. Int J Cancer 2002, 101, 353-359, doi:10.1002/ijc.10616.

44. Shih, L.B.; Xuan, H.; Aninipot, R.; Stein, R.; Goldenberg, D.M. In vitro and in vivo reactivity of an internalizing antibody, RS7, with human breast cancer. Cancer Res 1995, 55, 5857s-5863s.

45. Varughese, J.; Cocco, E.; Bellone, S.; Ratner, E.; Silasi, D.A.; Azodi, M.; Schwartz, P.E.; Rutherford, T.J.; Buza, N.; Pecorelli, S., et al. Cervical carcinomas overexpress human trophoblast cell-surface marker (Trop-2) and are highly sensitive to immunotherapy with hRS7, a humanized monoclonal anti-Trop-2 antibody. Am J Obstet Gynecol 2011, 205, 567.e561-567, doi:10.1016/j.ajog.2011.06.093.

46. Varughese, J.; Cocco, E.; Bellone, S.; de Leon, M.; Bellone, M.; Todeschini, P.; Schwartz, P.E.; Rutherford, T.J.; Pecorelli, S.; Santin, A.D. Uterine serous papillary carcinomas overexpress human trophoblast-cell-surface marker (Trop-2) and are highly sensitive to immunotherapy with hRS7, a humanized anti-Trop-2 monoclonal antibody. Cancer 2011, 117, 3163-3172, doi:10.1002/cncr.25891.

47. Varughese, J.; Cocco, E.; Bellone, S.; Bellone, M.; Todeschini, P.; Carrara, L.; Schwartz, P.E.; Rutherford, T.J.; Pecorelli, S.; Santin, A.D. High-grade, chemotherapyresistant primary ovarian carcinoma cell lines overexpress human trophoblast cellsurface marker (Trop-2) and are highly sensitive to immunotherapy with hRS7, a 
humanized monoclonal anti-Trop-2 antibody. Gynecol Oncol 2011, 122, 171-177, doi:10.1016/j.ygyno.2011.03.002.

48. Raji, R.; Guzzo, F.; Carrara, L.; Varughese, J.; Cocco, E.; Bellone, S.; Betti, M.; Todeschini, P.; Gasparrini, S.; Ratner, E., et al. Uterine and ovarian carcinosarcomas overexpressing Trop-2 are sensitive to hRS7, a humanized anti-Trop-2 antibody. $J$ Exp Clin Cancer Res 2011, 30, 106, doi:10.1186/1756-9966-30-106.

49. Bignotti, E.; Ravaggi, A.; Romani, C.; Falchetti, M.; Lonardi, S.; Facchetti, F.; Pecorelli, S.; Varughese, J.; Cocco, E.; Bellone, S., et al. Trop-2 overexpression in poorly differentiated endometrial endometrioid carcinoma: implications for immunotherapy with hRS7, a humanized anti-trop-2 monoclonal antibody. Int $J$ Gynecol Cancer 2011, 21, 1613-1621, doi:10.1097/IGC.0b013e318228f6da.

50. Stein, R.; Govindan, S.V.; Chen, S.; Reed, L.; Richel, H.; Griffiths, G.L.; Hansen, H.J.; Goldenberg, D.M. Radioimmunotherapy of a human lung cancer xenograft with monoclonal antibody RS7: evaluation of (177)Lu and comparison of its efficacy with that of (90)Y and residualizing (131)I. J Nucl Med 2001, 42, 967-974.

51. Govindan, S.V.; Stein, R.; Qu, Z.; Chen, S.; Andrews, P.; Ma, H.; Hansen, H.J.; Griffiths, G.L.; Horak, I.D.; Goldenberg, D.M. Preclinical therapy of breast cancer with a radioiodinated humanized anti-EGP-1 monoclonal antibody: advantage of a residualizing iodine radiolabel. Breast Cancer Res Treat 2004, 84, 173-182, doi:10.1023/B:BREA.0000018417.02580.ef.

52. Chang, C.H.; Gupta, P.; Michel, R.; Loo, M.; Wang, Y.; Cardillo, T.M.; Goldenberg, D.M. Ranpirnase (frog RNase) targeted with a humanized, internalizing, anti-Trop-2 antibody has potent cytotoxicity against diverse epithelial cancer cells. Mol Cancer Ther 2010, 9, 2276-2286, doi:10.1158/1535-7163.Mct-10-0338.

53. Lin, H.; Zhang, H.; Wang, J.; Lu, M.; Zheng, F.; Wang, C.; Tang, X.; Xu, N.; Chen, R.; Zhang, D., et al. A novel human Fab antibody for Trop2 inhibits breast cancer growth in vitro and in vivo. Int $J$ Cancer 2014, 134, 1239-1249, doi:10.1002/ijc.28451.

54. Truong, A.; Feng, N.; Sayegh, D.; Mak, B.; O'Reilly, K.; Fung, S.-W.; Ceric, N.; Hahn, S.; Pereira, D.; Findlay, H., et al. AR47A6.4.2, a functional naked monoclonal antibody targeting Trop-2, demonstrates $<\mathrm{em}>$ in vivo $</ \mathrm{em}>$ efficacy in human pancreatic, colon, breast and prostate cancer models. 2007, 6, PR-12-PR-12.

55. Ikeda, M.; Kato, K.; Yamaguchi, M.; Hamada, H.; Nakamura, K.; Sugimoto, Y. Cell Surface Antibody Retention Influences In Vivo Antitumor Activity Mediated by Antibody-dependent Cellular Cytotoxicity. Anticancer Res 2016, 36, 5937-5944, doi:10.21873/anticanres.11181.

56. Ikeda, M.; Yamaguchi, M.; Kato, K.; Nakamura, K.; Shiina, S.; Ichikawa-Ando, T.; Misaka, H.; Myojo, K.; Nakamura, K.; Sugimoto, Y., et al. Pr1E11, a novel anti-TROP2 antibody isolated by adenovirus-based antibody screening, recognizes a unique epitope. Biochem Biophys Res Commun 2015, 458, 877-882, doi:10.1016/j.bbrc.2015.02.051.

57. Müller, D.; Kontermann, R.E. Recombinant bispecific antibodies for cellular cancer immunotherapy. Curr Opin Mol Ther 2007, 9, 319-326.

58. Rossi, E.A.; Rossi, D.L.; Cardillo, T.M.; Chang, C.-H.; Goldenberg, D.M. Redirected T-Cell Killing of Solid Cancers Targeted with an Anti-CD3/Trop-2-Bispecific Antibody Is Enhanced in Combination with Interferon- $\alpha$. 2014, 13, 2341-2351, doi:10.1158/1535-7163.MCT-14-0345 \%J Molecular Cancer Therapeutics.

59. Rossi, D.L.; Cardillo, T.M.; Rossi, E.A.; Zalath, M.; Goldenberg, D.M.; Chang, C.-H. Abstract 2655: A novel Trop-2/CD3 trivalent bispecific antibody effectively redirects $\mathrm{T}$ cells to kill target human pancreatic and gastric cancer cells. 2014, 74, 2655-2655, doi:10.1158/1538-7445.AM2014-2655 \%J Cancer Research. 
60. Nagayama, A.; Ellisen, L.W.; Chabner, B.; Bardia, A. Antibody-Drug Conjugates for the Treatment of Solid Tumors: Clinical Experience and Latest Developments. Target Oncol 2017, 12, 719-739, doi:10.1007/s11523-017-0535-0.

61. Staudacher, A.H.; Brown, M.P. Antibody drug conjugates and bystander killing: is antigen-dependent internalisation required? Br J Cancer 2017, 117, 1736-1742, doi:10.1038/bjc.2017.367.

62. Campos, M.P.; Konecny, G.E. The target invites a foe: antibody-drug conjugates in gynecologic oncology. Curr Opin Obstet Gynecol 2018, 30, 44-50, doi:10.1097/gco.0000000000000432.

63. Masters, J.C.; Nickens, D.J.; Xuan, D.; Shazer, R.L.; Amantea, M. Clinical toxicity of antibody drug conjugates: a meta-analysis of payloads. Invest New Drugs 2018, 36, 121-135, doi:10.1007/s10637-017-0520-6.

64. Strop, P.; Tran, T.T.; Dorywalska, M.; Delaria, K.; Dushin, R.; Wong, O.K.; Ho, W.H.; Zhou, D.; Wu, A.; Kraynov, E., et al. RN927C, a Site-Specific Trop-2 Antibody-Drug Conjugate (ADC) with Enhanced Stability, Is Highly Efficacious in Preclinical Solid Tumor Models. Mol Cancer Ther 2016, 15, 2698-2708, doi:10.1158/1535-7163.Mct16-0431.

65. King, G.T.; Eaton, K.D.; Beagle, B.R.; Zopf, C.J.; Wong, G.Y.; Krupka, H.I.; Hua, S.Y.; Messersmith, W.A.; El-Khoueiry, A.B. A phase 1, dose-escalation study of PF06664178, an anti-Trop-2/Aur0101 antibody-drug conjugate in patients with advanced or metastatic solid tumors. Invest New Drugs 2018, 36, 836-847, doi:10.1007/s10637018-0560-6.

66. Goldenberg, D.M.; Cardillo, T.M.; Govindan, S.V.; Rossi, E.A.; Sharkey, R.M. Trop2 is a novel target for solid cancer therapy with sacituzumab govitecan (IMMU-132), an antibody-drug conjugate (ADC). Oncotarget 2015, 6, 22496-22512, doi:10.18632/oncotarget.4318.

67. Syed, Y.Y. Sacituzumab Govitecan: First Approval. Drugs 2020, 80, 1019-1025, doi:10.1007/s40265-020-01337-5.

68. Bardia, A.; Mayer, I.A.; Vahdat, L.T.; Tolaney, S.M.; Isakoff, S.J.; Diamond, J.R.; O'Shaughnessy, J.; Moroose, R.L.; Santin, A.D.; Abramson, V.G., et al. Sacituzumab Govitecan-hziy in Refractory Metastatic Triple-Negative Breast Cancer. N Engl J Med 2019, 380, 741-751, doi:10.1056/NEJMoa1814213.

69. Starodub, A.N.; Ocean, A.J.; Shah, M.A.; Guarino, M.J.; Picozzi, V.J., Jr.; Vahdat, L.T.; Thomas, S.S.; Govindan, S.V.; Maliakal, P.P.; Wegener, W.A., et al. First-inHuman Trial of a Novel Anti-Trop-2 Antibody-SN-38 Conjugate, Sacituzumab Govitecan, for the Treatment of Diverse Metastatic Solid Tumors. Clin Cancer Res 2015, 21, 3870-3878, doi:10.1158/1078-0432.Ccr-14-3321.

70. Ocean, A.J.; Starodub, A.N.; Bardia, A.; Vahdat, L.T.; Isakoff, S.J.; Guarino, M.; Messersmith, W.A.; Picozzi, V.J.; Mayer, I.A.; Wegener, W.A., et al. Sacituzumab govitecan (IMMU-132), an anti-Trop-2-SN-38 antibody-drug conjugate for the treatment of diverse epithelial cancers: Safety and pharmacokinetics. Cancer 2017, 123, 3843-3854, doi:10.1002/cncr.30789.

71. Bardia, A.; Diamond, J.R.; Vahdat, L.T.; Tolaney, S.M.; O'Shaughnessy, J.; Moroose, R.L.; Mayer, I.A.; Abramson, V.G.; Juric, D.; Sharkey, R.M., et al. Efficacy of sacituzumab govitecan (anti-Trop-2-SN-38 antibody-drug conjugate) for treatmentrefractory hormone-receptor positive $(\mathrm{HR}+) / \mathrm{HER} 2-$ metastatic breast cancer $(\mathrm{mBC})$. 2018, 36, 1004-1004, doi:10.1200/JCO.2018.36.15_suppl.1004.

72. Heist, R.S.; Guarino, M.J.; Masters, G.; Purcell, W.T.; Starodub, A.N.; Horn, L.; Scheff, R.J.; Bardia, A.; Messersmith, W.A.; Berlin, J., et al. Therapy of Advanced Non-Small-Cell Lung Cancer With an SN-38-Anti-Trop-2 Drug Conjugate, 
Sacituzumab Govitecan. J Clin Oncol 2017, 35, 2790-2797, doi:10.1200/jco.2016.72.1894.

73. Gray, J.E.; Heist, R.S.; Starodub, A.N.; Camidge, D.R.; Kio, E.A.; Masters, G.A.; Purcell, W.T.; Guarino, M.J.; Misleh, J.; Schneider, C.J., et al. Therapy of Small Cell Lung Cancer (SCLC) with a Topoisomerase-I-inhibiting Antibody-Drug Conjugate (ADC) Targeting Trop-2, Sacituzumab Govitecan. Clin Cancer Res 2017, 23, 57115719, doi:10.1158/1078-0432.Ccr-17-0933.

74. Tagawa, S.T.; Faltas, B.M.; Lam, E.T.; Saylor, P.J.; Bardia, A.; Hajdenberg, J.; Morgans, A.K.; Lim, E.A.; Kalinsky, K.; Simpson, P.S., et al. Sacituzumab govitecan (IMMU-132) in patients with previously treated metastatic urothelial cancer (mUC): Results from a phase I/II study. 2019, 37, 354-354, doi:10.1200/JCO.2019.37.7_suppl.354.

75. Tagawa, S.T.; Petrylak, D.P.; Grivas, P.; Agarwal, N.; Sternberg, C.N.; SiemonHryczyk, P.; Goswam, T.; Loriot, Y. TROPHY-u-01: A phase II open-label study of sacituzumab govitecan (IMMU-132) in patients with advanced urothelial cancer after progression on platinum-based chemotherapy and/or anti-PD-1/PD-L1 checkpoint inhibitor therapy. 2019, 37, TPS495-TPS495, doi:10.1200/JCO.2019.37.7_suppl.TPS495.

76. Tagawa, S.; Balar, A.; Petrylak, D.; Grivas, P.; Agarwal, N.; Sternberg, C.; Hong, Q.; Gladden, A.; Kanwal, C.; Siemon-Hryczyk, P.J.A.o.O. Initial results from TROPHYU-01: A phase II open-label study of sacituzumab govitecan in patients (Pts) with metastatic urothelial cancer (mUC) after failure of platinum-based regimens (PLT) or immunotherapy. 2019, 30, v890-v891.

77. Petrylak, D.P.; Tagawa, S.T.; Jain, R.K.; Bupathi, M.; Balar, A.V.; Rezazadeh, A.; George, S.; Palmbos, P.L.; Nordquist, L.T.; Davis, N.B., et al. Early results of TROPHY-U-01 Cohort 2: Sacituzumab govitecan (SG) in platinum-ineligible patients (pts) with metastatic urothelial cancer (mUC) who progressed after prior checkpoint inhibitor (CPI) therapy. 2020, 38, 5027-5027, doi:10.1200/JCO.2020.38.15_suppl.5027.

78. Rugo, H.S.; Bardia, A.; Tolaney, S.M.; Arteaga, C.; Cortes, J.; Sohn, J.; Marmé, F.; Hong, Q.; Delaney, R.J.; Hafeez, A., et al. TROPiCS-02: A Phase III study investigating sacituzumab govitecan in the treatment of HR+/HER2- metastatic breast cancer. Future Oncol 2020, 16, 705-715, doi:10.2217/fon-2020-0163.

79. Cardillo, T.M.; Govindan, S.V.; Sharkey, R.M.; Trisal, P.; Goldenberg, D.M. Humanized anti-Trop-2 IgG-SN-38 conjugate for effective treatment of diverse epithelial cancers: preclinical studies in human cancer xenograft models and monkeys. Clin Cancer Res 2011, 17, 3157-3169, doi:10.1158/1078-0432.Ccr-10-2939.

80. Stein, A.; Voigt, W.; Jordan, K. Chemotherapy-induced diarrhea: pathophysiology, frequency and guideline-based management. Ther Adv Med Oncol 2010, 2, 51-63, doi:10.1177/1758834009355164.

81. Okajima, D.; Yamaguchi, J.; Kitamura, M.; Kamei, R.; Maejima, T.; Shibutani, T.; Yasuda, S.; Toki, T.; Karibe, T.; Fujitani, T., et al. Abstract C026: DS-1062a, a novel TROP2-targeting antibody-drug conjugate with a novel DNA topoisomerase I inhibitor DXd, demonstrates potent antitumor activity in preclinical models. 2019, 18, C026C026, doi:10.1158/1535-7163.TARG-19-C026 \%J Molecular Cancer Therapeutics.

82. Sands, J.M.; Shimizu, T.; Garon, E.B.; Greenberg, J.; Guevara, F.M.; Heist, R.S.; Kobayashi, F.; Noguchi, Y.; Okajima, D.; Tajima, N., et al. First-in-human phase 1 study of DS-1062a in patients with advanced solid tumors. 2019, 37, 9051-9051, doi:10.1200/JCO.2019.37.15_suppl.9051. 
83. Lisberg, A.E.; Sands, J.; Shimizu, T.; Greenberg, J.; Phillips, P.; Guevara, F.M.; Noguchi, Y.; Toki, T.; Spira, A.I.; Yamamoto, N., et al. Dose escalation and expansion from the phase I study of DS-1062, a trophoblast cell-surface antigen 2 (TROP2) antibody drug conjugate (ADC), in patients (pts) with advanced non-small cell lung cancer (NSCLC). 2020, 38, 9619-9619, doi:10.1200/JCO.2020.38.15_suppl.9619.

84. Tang, W.; Huang, X.; Ou, Z.; Yan, H.; Gan, J.; Dong, Q.; Tan, B.; Yang, Y.; Guo, Y.; Li, S., et al. Abstract P6-20-16: BAT8003, a potent anti-Trop-2 antibody-drug conjugate, for the treatment of triple negative breast cancer. 2019, 79, P6-20-16-P2620-16, doi:10.1158/1538-7445.SABCS18-P6-20-16 \%J Cancer Research.

85. Cardillo, T.M.; Govindan, S.V.; Sharkey, R.M.; Trisal, P.; Arrojo, R.; Liu, D.; Rossi, E.A.; Chang, C.H.; Goldenberg, D.M. Sacituzumab Govitecan (IMMU-132), an AntiTrop-2/SN-38 Antibody-Drug Conjugate: Characterization and Efficacy in Pancreatic, Gastric, and Other Cancers. Bioconjug Chem 2015, 26, 919-931, doi:10.1021/acs.bioconjchem.5b00223.

86. Liu, Y.; Lian, W.; Zhao, X.; Diao, Y.; Xu, J.; Xiao, L.; Qing, Y.; Xue, T.; Wang, J. SKB264 ADC: A first-in-human study of SKB264 in patients with locally advanced unresectable/metastatic solid tumors who are refractory to available standard therapies. 2020, 38, TPS3659-TPS3659, doi:10.1200/JCO.2020.38.15_suppl.TPS3659.

87. Bedoya, D.M.; King, T.; Posey, A.D. Generation of CART cells targeting oncogenic TROP2 for the elimination of epithelial malignancies. Cytotherapy 2019, 21, S11-S12, doi:https://doi.org/10.1016/j.jcyt.2019.03.570.

88. Zhao, W.; Jia, L.; Zhang, M.; Huang, X.; Qian, P.; Tang, Q.; Zhu, J.; Feng, Z. The killing effect of novel bi-specific Trop2/PD-L1 CAR-T cell targeted gastric cancer. Am J Cancer Res 2019, 9, 1846-1856.

89. Lee, J.K.; Bangayan, N.J.; Chai, T.; Smith, B.A.; Pariva, T.E.; Yun, S.; Vashisht, A.; Zhang, Q.; Park, J.W.; Corey, E., et al. Systemic surfaceome profiling identifies target antigens for immune-based therapy in subtypes of advanced prostate cancer. Proc Natl Acad Sci U S A 2018, 115, E4473-e4482, doi:10.1073/pnas.1802354115.

90. Han, Z.W.; Lyv, Z.W.; Cui, B.; Wang, Y.Y.; Cheng, J.T.; Zhang, Y.; Cai, W.Q.; Zhou, Y.; Ma, Z.W.; Wang, X.W., et al. The old CEACAMs find their new role in tumor immunotherapy. Invest New Drugs 2020, 10.1007/s10637-020-00955-w, doi:10.1007/s10637-020-00955-w.

91. Thistlethwaite, F.C.; Gilham, D.E.; Guest, R.D.; Rothwell, D.G.; Pillai, M.; Burt, D.J.; Byatte, A.J.; Kirillova, N.; Valle, J.W.; Sharma, S.K., et al. The clinical efficacy of first-generation carcinoembryonic antigen (CEACAM5)-specific CAR $\mathrm{T}$ cells is limited by poor persistence and transient pre-conditioning-dependent respiratory toxicity. Cancer Immunol Immunother 2017, 66, 1425-1436, doi:10.1007/s00262-0172034-7.

92. Hsu, E.C.; Rice, M.A.; Bermudez, A.; Marques, F.J.G.; Aslan, M.; Liu, S.; Ghoochani, A.; Zhang, C.A.; Chen, Y.S.; Zlitni, A., et al. Trop2 is a driver of metastatic prostate cancer with neuroendocrine phenotype via PARP1. Proc Natl Acad Sci U S A 2020, 117, 2032-2042, doi:10.1073/pnas.1905384117.

93. Liu, J.N.; Wang, H.B.; Zhou, C.C.; Hu, S.Y. CEACAM5 has different expression patterns in gastric non-neoplastic and neoplastic lesions and cytoplasmic staining is a marker for evaluation of tumor progression in gastric adenocarcinoma. Pathol Res Pract 2014, 210, 686-693, doi:10.1016/j.prp.2014.06.024.

94. Wang, X.; Long, M.; Dong, K.; Lin, F.; Weng, Y.; Ouyang, Y.; Liu, L.; Wei, J.; Chen, $\mathrm{X}$; He, T., et al. Chemotherapy agents-induced immunoresistance in lung cancer cells could be reversed by trop-2 inhibition in vitro and in vivo by interaction with MAPK signaling pathway. Cancer Biol Ther 2013, 14, 1123-1132, doi:10.4161/cbt.26341. 
95. Guerra, E.; Trerotola, M.; Tripaldi, R.; Aloisi, A.L.; Simeone, P.; Sacchetti, A.; Relli, V.; D'Amore, A.; La Sorda, R.; Lattanzio, R., et al. Trop-2 Induces Tumor Growth Through AKT and Determines Sensitivity to AKT Inhibitors. Clin Cancer Res 2016, 22, 4197-4205, doi:10.1158/1078-0432.Ccr-15-1701.

96. Chang, C.H.; Wang, Y.; Zalath, M.; Liu, D.; Cardillo, T.M.; Goldenberg, D.M. Combining ABCG2 Inhibitors with IMMU-132, an Anti-Trop-2 Antibody Conjugate of SN-38, Overcomes Resistance to SN-38 in Breast and Gastric Cancers. Mol Cancer Ther 2016, 15, 1910-1919, doi:10.1158/1535-7163.Mct-16-0219.

97. Cardillo, T.M.; Sharkey, R.M.; Rossi, D.L.; Arrojo, R.; Mostafa, A.A.; Goldenberg, D.M. Synthetic Lethality Exploitation by an Anti-Trop-2-SN-38 Antibody-Drug Conjugate, IMMU-132, Plus PARP Inhibitors in BRCA1/2-wild-type Triple-Negative Breast Cancer. Clin Cancer Res 2017, 23, 3405-3415, doi:10.1158/1078-0432.Ccr-162401.

98. Vidmar, T.; Pavšič, M.; Lenarčič, B. Biochemical and preliminary X-ray characterization of the tumor-associated calcium signal transducer 2 (Trop2) ectodomain. Protein Expr Purif 2013, 91, 69-76, doi:10.1016/j.pep.2013.07.006.

99. Linnenbach, A.J.; Wojcierowski, J.; Wu, S.A.; Pyrc, J.J.; Ross, A.H.; Dietzschold, B.; Speicher, D.; Koprowski, H. Sequence investigation of the major gastrointestinal tumor-associated antigen gene family, GA733. Proc Natl Acad Sci U S A 1989, 86, 27 31, doi:10.1073/pnas.86.1.27.

100. Cubas, R.; Zhang, S.; Li, M.; Chen, C.; Yao, Q. Trop2 expression contributes to tumor pathogenesis by activating the ERK MAPK pathway. Mol Cancer 2010, 9, 253, doi:10.1186/1476-4598-9-253.

101. Bakiri, L.; Macho-Maschler, S.; Custic, I.; Niemiec, J.; Guío-Carrión, A.; Hasenfuss, S.C.; Eger, A.; Müller, M.; Beug, H.; Wagner, E.F. Fra-1/AP-1 induces EMT in mammary epithelial cells by modulating Zeb1/2 and TGF $\beta$ expression. Cell Death Differ 2015, 22, 336-350, doi:10.1038/cdd.2014.157.

102. Stoyanova, T.; Goldstein, A.S.; Cai, H.; Drake, J.M.; Huang, J.; Witte, O.N. Regulated proteolysis of Trop2 drives epithelial hyperplasia and stem cell self-renewal via $\beta$ catenin signaling. Genes Dev 2012, 26, 2271-2285, doi:10.1101/gad.196451.112.

103. Vidula, N.; Yau, C.; Rugo, H.S. Trop2 gene expression (Trop2e) in primary breast cancer (BC): Correlations with clinical and tumor characteristics. 2017, 35, 1075-1075, doi:10.1200/JCO.2017.35.15_suppl.1075.

104. Xu, N.; Zhang, Z.; Zhu, J.; Xu, L.; Li, Y.; Duan, L.; Mao, Y.; Li, H. Overexpression of trophoblast cell surface antigen 2 as an independent marker for a poor prognosis and as a potential therapeutic target in epithelial ovarian carcinoma. Int J Exp Pathol 2016, 97, 150-158, doi:10.1111/iep.12174.

105. Faltas, B.; Goldenberg, D.M.; Ocean, A.J.; Govindan, S.V.; Wilhelm, F.; Sharkey, R.M.; Hajdenberg, J.; Hodes, G.; Nanus, D.M.; Tagawa, S.T. Sacituzumab Govitecan, a Novel Antibody--Drug Conjugate, in Patients With Metastatic Platinum-Resistant Urothelial Carcinoma. Clin Genitourin Cancer 2016, 14, e75-79, doi:10.1016/j.clgc.2015.10.002.

106. Bychkov, A.; Sampatanukul, P.; Shuangshoti, S.; Keelawat, S. TROP-2 immunohistochemistry: a highly accurate method in the differential diagnosis of papillary thyroid carcinoma. Pathology 2016, 48, 425-433, doi:10.1016/j.pathol.2016.04.002.

107. Fong, D.; Spizzo, G.; Gostner, J.M.; Gastl, G.; Moser, P.; Krammel, C.; Gerhard, S.; Rasse, M.; Laimer, K. TROP2: a novel prognostic marker in squamous cell carcinoma of the oral cavity. Mod Pathol 2008, 21, 186-191, doi:10.1038/modpathol.3801001. 
108. Mühlmann, G.; Spizzo, G.; Gostner, J.; Zitt, M.; Maier, H.; Moser, P.; Gastl, G.; Zitt, M.; Müller, H.M.; Margreiter, R., et al. TROP2 expression as prognostic marker for gastric carcinoma. J Clin Pathol 2009, 62, 152-158, doi:10.1136/jcp.2008.060590.

109. Goldenberg, D.M.; Sharkey, R.M. Sacituzumab govitecan, a novel, third-generation, antibody-drug conjugate (ADC) for cancer therapy. Expert Opin Biol Ther 2020, 20, 871-885, doi:10.1080/14712598.2020.1757067.

110. Kalinsky, K.; Isakoff, S.; Tolaney, S.; Juric, D.; Mayer, I.; Vahdat, L.; Diamond, J.; O'Shaughnessy, J.; Moroose, R.; Santin, A., et al. Abstract P2-11-01: Safety and efficacy of sacituzumab govitecan (anti-Trop-2-SN-38 antibody-drug conjugate) as $\geqslant$ $3<$ sup $>$ rd $</$ sup $>$-line therapeutic option for treatment-refractory HER2-negative metastatic breast cancer (HER2Neg mBC). 2019, 79, P2-11-01-P12-11-01, doi:10.1158/1538-7445.SABCS18-P2-11-01 \%J Cancer Research. 